\title{
1 Diversity of fish sound types in the Pearl River Estuary,
}

\section{China}

4 Authors

5 Zhi-Tao Wang ${ }^{1^{*}}$, Douglas P. Nowacek ${ }^{2,3}$, TomonariAkamatsu ${ }^{4}$, Ke-Xiong Wang ${ }^{1}$, Jian-Chang

6 Liu $^{5}$, Guo-Qin Duan ${ }^{6}$, Han-Jiang $\mathrm{Cao}^{6}$, Ding Wang ${ }^{1}$

$7 \quad{ }^{1}$ The Key Laboratory of Aquatic Biodiversity and Conservation of the Chinese Academy of

8 Sciences, Institute of Hydrobiology of the Chinese Academy of Sciences, Wuhan, P. R. China

$9 \quad{ }^{2}$ Division of Marine Science and Conservation, Nicholas School of the Environment, Duke

University of Marine Laboratory, Beaufort, NC, USA

$11{ }^{3}$ Pratt School of Engineering, Duke University, Durham, NC, USA

$12{ }^{4}$ National Research Institute of Fisheries Science, Fisheries Research and Development Agency,

13 Kanagawa, Japan

$14{ }^{5}$ Transport Planning and Research Institute, Ministry of Transport, Beijing, P. R. China

$15{ }^{6}$ Hong Kong-Zhuhai-Macao Bridge Authority, Guangzhou, P. R. China

* also at Nicholas School of the Environment, Duke University, Beaufort, NC, USA

17 Corresponding Authors:

18 Ke-Xiong Wang and Ding Wang

19 7\# Donghu South Road, Wuhan, Hubei, 430074, China

20 Email addresses: wangk@ihb.ac.cn (K.X.W.); wangd@ihb.ac.cn (D.W.) 


\section{Abstract}

22 Background. Repetitive species-specific sound enables the identification of the presence and

behavior of soniferous species by acoustic means. Passive acoustic monitoring has been widely applied to monitor the spatial and temporal occurrence and behavior of calling species.

Methods. Underwater biological sounds in the Pearl River Estuary, China, were collected using passive acoustic monitoring, with special attention paid to fish sounds. A total of 1408 suspected fish calls comprising 18,942 pulses were qualitatively analyzed using a customized acoustic analysis routine.

Results. We identified a diversity of 66 types of fish sounds. In addition to single pulse, the sounds tended to have a pulse train structure. The pulses were characterized by an approximate $8 \mathrm{~ms}$ duration, with a peak frequency from 500 to $2600 \mathrm{~Hz}$ and a majority of the energy below $4000 \mathrm{~Hz}$. The median inter-pulsepeak interval (IPPI) of most call types was 9 or 10 ms. Most call types with median IPPIs of $9 \mathrm{~ms}$ and $10 \mathrm{~ms}$ were observed at times that were exclusive from each other, suggesting that they might be produced by different species. According to the literature, the two section signal types of $1+1$ and $1+\mathrm{N}_{10}$ might belong to big-snout croaker (Johnius macrorhynus), and $1+\mathrm{N}_{19}$ might be produced by Belanger's croaker (J. belangerii).

Discussion. Categorization of the baseline ambient biological sound is an important first step in mapping the spatial and temporal patterns of soniferous fishes. The next step is the identification of the species producing each sound. The distribution pattern of soniferous fishes will be helpful for the protection and management of local fishery resources and in marine environmental impact assessment. Since the local vulnerable Indo-Pacific humpback dolphin (Sousa chinensis) mainly preys on soniferous fishes, the fine-scale distribution pattern of soniferous fishes can aid in the 
database of species-identified sounds is completed.

Running title: Diversity of fish sounds in China 


\section{6 \\ Introduction}

The Pearl River Estuary $\left(21^{\circ} 40^{\prime}-22^{\circ} 50^{\prime} \mathrm{N} ; 112^{\circ} 50^{\prime}-114^{\circ} 30^{\prime} \mathrm{E}\right)$ is in a subtropical area of the northern South China Sea. The estuary is one of the most economically developed regions in China, and the rapid local industrialization and large-scale infrastructure projects, e.g., the ongoing construction of the Hong Kong-Zhuhai-Macao bridge (Wang et al. 2014b) and the Guishan wind farm project (Wang et al. 2015b), have placed an extraordinarily heavy burden on coastal environments and accelerated human damage to coastal ecosystems. courtship and spawning) and territorial or aggressive behavior (Hawkins \& Amorim 2000; Takemura et al. 1978). Most of the repetitive fish sounds are species specific (Tavolga 1964), which enables the identification of the distribution and behavior of soniferous species by acoustic means. As a noninvasive technology, passive acoustic monitoring has been widely applied to map the spatial (over a wide range of habitats and at varied depths) (Wall et al. 2012; Wall et al. 2013) and temporal (diel, seasonal and annual) (Locascio \& Mann 2011; Ruppé et al. 2015; Turnure et al. 2015) occurrence and behavior of soniferous fishes, even in severe conditions. wild fisheries of China (Liu \& Sadovy 2008; Sadovy \& Cheung 2003). The endemic species of giant yellow croaker (Bahaba taipingensis), which is highly valued as a traditional medicine of its swim bladder and was an important fish stock before the 1960s, collapsed in the wild and was determined to be commercially extinct in 1997 (Sadovy \& Cheung 2003). The spotted drum (Protonibea diacanthus) and large yellow croaker (Larimichthys crocea which is endemic to East Asia and was

67 once one of the three top commercial marine fishes in China), have been severely depleted

Deleted: Pseudosciaena crocea 
throughout their geographic range since the 1980s and have now almost entirely disappeared from landings (Liu \& Sadovy 2008; Sadovy \& Cheung 2003). The most recent study of Indo-Pacific humpback dolphins (Sousa chinensis, locally called the Chinese white dolphin) biosonar activity in the Pearl River Estuary indicated that its diel, seasonal and tidal patterns might be ascribed to the spatial-temporal variability of its prey (Wang et al. 2015b); however, little attention has been paid to local fishes, with only sporadic fishery distribution data with poor temporal and spatial resolution obtained from 1986-1987 by bottom trawl and in 1998 by beam trawl and hang trawl (Li et al. 2000b; Wang \& Lin 2006).The fine-scale distribution pattern of humpback dolphin prey has yet to be investigated.

In this study, the ambient biological sounds in the Pearl River Estuary were recorded using passive acoustic monitoring. Suspected fish sounds were quantitatively and qualitatively characterized. We compared the species-specific sounds thorough a literature review, especially of those species that are distributed in the research area, to confirm the caller's identity. These baseline data can serve as a first step toward mapping the spatial and temporal distribution patterns of soniferous fishes in the estuary. Moreover, they are helpful for planning fisheries management and evaluation of the damage to aquatic environments (e.g., spawning grounds of the sciaenids) from various large-scale infrastructure projects because marine environmental impact assessments must be based upon a good understanding of the local baseline biodiversity. Additionally, the baseline data can aid in the protection of local humpback dolphins and the implementation of conservation strategies.

\section{Methods}

\section{Deleted:}

Deleted: (signature) 


\section{Acoustic data recording system}

Underwater acoustic recordings were made using a Song Meter Marine Recorder (Wildlife Acoustics, Inc., Maynard, MA, USA), which included an HTI piezoelectric omnidirectional hydrophone (model HTI-96-MIN; High Tech, Inc., Long Beach, MS, USA) with a sensitivity of $164 \mathrm{~dB}$ re $1 \mathrm{~V} / \mu \mathrm{Pa}$ at $1 \mathrm{~m}$ distance, a recording bandwidth of $2 \mathrm{~Hz}-48 \mathrm{kHz}$ and a flat frequency response over a wide range of $2 \mathrm{~Hz}-37 \mathrm{kHz}( \pm 3 \mathrm{~dB})$. The hydrophone also included a programmable autonomous signal processing unit integrated with a band-pass filter and a pre-amplifier. The signal processing unit can log data at a resolution of 16 bits and at a $96 \mathrm{kHz}$ sampling rate, with a storage capacity of 512 GB. The signal processing unit was sealed inside a waterproof PVC housing and was submersible to $150 \mathrm{~m}$. The recording system was calibrated prior to shipment from the manufacturer.

\section{Data collection}

Static acoustic monitoring was conducted underwater at the base of a telephone signal tower $\left(22^{\circ} 07^{\prime} 54^{\prime \prime} \mathrm{N}, 113^{\circ} 43^{\prime} 54^{\prime \prime}\right.$ E) located among the Sanjiao, Chitan and Datou islands (Fig. 1).The recordings were taken continuously throughout deployment periods from May 26 to June 4, 2014, and June 17 to 22,2014 , at a $96 \mathrm{kHz}$ sampling rate. The acoustic recording system was attached to a steel wire rope and suspended below the signal tower in the middle of water column $4.0 \mathrm{~m}$ above the ocean floor and approximately 3.0 to $5.8 \mathrm{~m}$ (depending on the tide conditions) below the water surface. A $40 \mathrm{~kg}$ anchor block was attached on the bottom of the steel wire rope and laid down on the seabed to reduce the movement of the recording system due to water currents.

\section{Acoustic data analysis}



initially visualize the acoustic data in the spectrogram (window type: Hann windows; fast Fourier transform (FFT) size: 2048 samples; frame overlapping: 80\%; frequency grid spacing: $46.88 \mathrm{~Hz}$; temporal grid resolution: $4.26 \mathrm{~ms}$ ). Only calls with good signal-to-noise ratios ( $\mathrm{SNR}>15 \mathrm{~dB}$, noise level obtained just before or after the pulse) and satisfying the criteria of no interference by other sounds were extracted for further quantitative analyses. To make the data more independent and reduce the possibility of using multiple sounds from the same individual, only one signal was extracted for each call type in every $10 \mathrm{~min}$ bin for further analysis. analysis routine based on MATLAB 7.11.0 (The Mathworks, Natick, MA, USA) was developed to analyze the extracted calls. For each call, the peak amplitude time for each pulse within the call was logged using a pulse-peak detector. Through trial and error, the pulse was defined and extracted as an $8 \mathrm{~ms}$ signal that began $2.5 \mathrm{~ms}$ before and ended $5.5 \mathrm{~ms}$ after the time point of the peak amplitude (Fig. 2B and C). The $8 \mathrm{~ms}$ definition was validated because it encompassed the majority of the energy of a pulse and was longer than the shortest interval between pulses within a call. The sonic parameters of the number of pulses in a call, total call duration (in ms), inter-pulsepeak interval (IPPI), and the inter-pulse interval (IPI) were calculated for each call. Call duration is derived by adding $8 \mathrm{~ms}$ to the time difference of the last pulsepeak and the first pulsepeak, IPPI is the time difference between the peak amplitude of consecutive pulse units in the train, which is equal to the pulse period in the literature(Parmentier et al. 2009), and IPI is the time interval between the end of

Deleted: Total c 
were computed as $\tau_{95 \%}, \tau_{-3 \mathrm{~dB}}$ and $\tau_{-10 \mathrm{~dB}} . \tau_{95 \%}$ is the duration containing $95 \%$ of the cumulative energy of the pulse (Fig. 2D), which began when $2.5 \%$ of the cumulative signal energy was reached ( $\mathrm{CE}_{2.5 \%}$ in Fig. 2D) and ended when $97.5 \%$ of the cumulative signal energy was reached (CE97.5\% in Fig. $2 \mathrm{D})$, and $\tau_{-3 \mathrm{~dB}}$ and $\tau_{-10 \mathrm{~dB}}$ are the time differences between the end points that were $3 \mathrm{~dB}$ and $10 \mathrm{~dB}$ lower than the peak amplitude of the envelope of the pulse waveform, respectively (Fig. 2E). The signal envelope was generated by taking the absolute value of the waveform after applying the Hilbert transform function ( $\mathrm{Au}$ 1993; Madsen \& Wahlberg 2007). The frequency and bandwidth properties for each $8 \mathrm{~ms}$ pulse were determined from the power spectrum, which was calculated from the squared fast Fourier transform of a 96,000-point Hanning window. Parameters of the peak frequency ( $f_{p}$, the frequency at which the spectrum has its maximum value) (Fig. 2F), center frequency $\left(f_{c}\right.$, the frequency that divides the power spectrum into equal energy halves) and centralized root-mean-square bandwidth $\left(\mathrm{BW}_{\mathrm{rms}}\right.$, the spectral standard deviation of the $\mathrm{f}_{\mathrm{c}}$ of the spectrum) (Au 1993; Madsen \& Wahlberg 2007) were measured since they were proposed to be good descriptive parameters for signals with bimodal spectra (Au 2004). Parameters of 3-dB and 10-dB bandwidths were not measured since they might only cover the frequency range near the peak frequency and tend to provide a misrepresentation of the bandwidth of signals with bimodal spectra (Au 2004). The quality factor of each pulse (Q, an appropriate way to define the relative width of a signal) was computed as the ratio of the $\mathrm{f}_{\mathrm{c}}$ to the $\mathrm{BW}$ rms $(\mathrm{Au} 1993$; $\mathrm{Au}$ 2004). The sound pressure levels (SPLs, $\mathrm{dB}$ re $1 \mu \mathrm{Pa}$ ) and energy flux density (EFD, $\mathrm{dB}$ re $1 \mu \mathrm{Pa}^{2} \mathrm{~s}$ ) were derived for each $8 \mathrm{~ms}$ pulse over its $\tau_{95 \%}$. The SPL parameters included the zero-to-peak SPL $\left(\mathrm{SPL}_{\mathrm{zp}}\right)$ and the root-meansquare SPL (SPLrms) (Urick 1983). The absolute pressure levels were derived by subtracting the sensitivity of the hydrophone and the gain due to the amplifier (Urick 1983). 

peak mode, with a distribution curve peaking at 9, 10, 12, 13 and $18 \mathrm{~ms}$ (Fig. 3A). Previous experience in fish acoustic analysis by other investigators indicated that the IPPI was the most reliable basis for signal identification and species-specific recognition (Mann \& Lobel 1997;

Parmentier et al. 2009; Spanier 1979), and most signals in our database ended with a pulse train featuring regular IPPIs (Table 1). In this study, calls were classified into types primarily based on their IPPI patterns and their amplitude and temporal modulation patterns (Table 1). The calls were initially grouped according to the number of sections they contained (Table 1). For each call, pulses with IPPIs greater than 1.5 times the median IPPI of the call were divided into different sections. Based on the bimodal distribution of the IPPI for calls that consisted of fewer than three pulses, pulses with an IPPI greater than $24 \mathrm{~ms}$ (three times the duration of a single pulse of $8 \mathrm{~ms}$ ) were divided into different sections (Fig. 3B). To name each call type, such as $2+1+\mathrm{N}_{10},(1-)^{4}+(2-)^{2}+\mathrm{N}_{10}$ and ${ }^{\mathrm{i}} \mathrm{N}_{13}$ (Figs . 4-6, Fig.. S1- S26), '+' was used to separate the different sections of a call, a number was used to denote the number of pulses for that section and '(1-)' and '(2-)' to denote repeated sections that consist of one or two pulses, respectively, with digital superscripts denoting the number of repeats in a repeating section. ' $\mathrm{N}$ ' was used to denote the last section of a call with a variable number of pulses, and the digital subscripts denote the median IPPIs of the last portion of the call; the subscript "i" was used to denote calls with a zero-to-peak sound pressure level of the first pulse approximately $10 \mathrm{~dB}$ weaker than that of the remainder of the call. Occasionally, a train of calls was extracted with significantly higher $\mathrm{SNR}(\mathrm{SNR}>25 \mathrm{~dB})$, a regular inter-call interval, and a gradually changing pattern in its sound pressure level distinct from the ambient biological sounds. 
These sounds were likely produced by the same individual fish, which facilitated the estimation of the inter-call intervals.

\section{Statistical analysis}

Descriptive statistics were used to summarize the biographical information. All the parameters were tested for normality (using the Shapiro-Wilk test for data sets $<50$ or the KolmogorovSmirnov test for data sets $\geq 50$ ) and homoscedasticity (using Levene's test for equality of variance) (Zar 1999). Because of the grossly skewed distribution of the majority of the data, the descriptive parameters of median, quartile deviation (QD), 5th percentile (P5), and 95th percentile (P95) were adopted. The QD was defined as one-half the interquartile range, which is the difference between the 25 th and 75 th percentiles in a frequency distribution.

Principal component analysis was used to identify the variables explaining the most variance among the acoustic parameters. Call types with an analyzed number greater than five were extracted for further discriminant and cluster analyses. Canonical discriminant analysis was used to assess the variation among call types relative to the variation within call types and determine the validity of our call types. Hierarchical cluster analysis (Romesburg 2004), a step-wise process that merges the two closest or furthest data points at each step and builds a hierarchy of clusters based on the distance between them, was applied to discover similar call types in each set. Because the amplitude parameters were not critical for species recognition (Ha 1973) and the call duration was dependent on the number of pulses in a call (Parmentier et al. 2009), these parameters were not included in the principal component analysis, canonical discriminant analysis and hierarchical cluster analysis. The statistical analyses were performed using Statistical Package for the Social Sciences 16.0 for 


\section{Results}

\section{Single-section calls}

\section{Two-section calls}

Ambient biological sounds and suspected fish sounds were recorded over 16 days and sometimes formed dense choruses of individual sound emissions produced simultaneously and/or overlapping with each other that obscured the signals and could not be discriminated individually, especially before dusk. In addition to some single pulses, individual calls tended to possess a multi-pulse burst structure. The most representative pulse consisted of 6 oscillations (Fig. 2C). Owing to the single hydrophone methodology, animal localization was not possible in this study. The recorded sound was occasionally clipped, indicating that the source level of the sound was higher than $164 \mathrm{~dB}$ (limited by the hydrophone sensitivity). A total of 1408 calls comprising 18,942 pulses were extracted for statistical analysis and were categorized into 66 call types (Table 1).

Calls that consisted of a single section included call types 1,2 (Table S1, Fig.S1), $\mathrm{N}_{9}, \mathrm{~N}_{10}, \mathrm{~N}_{13}$, $\mathrm{N}_{17}$ (Table 2, Fig.4), ${ }^{\mathrm{i}} \mathrm{N}_{13}$ and ${ }^{\mathrm{i}} \mathrm{N}_{15}$ (Table 3, Fig.5).

Calls consisting of two sections included call types $1+1$ (Table S1, Fig.S1), $1+\mathrm{N}_{10}, 1+\mathrm{N}_{12}, 1+\mathrm{N}_{19}$ (Table 4, Fig.6), $2+\mathrm{N}_{9}, 2+\mathrm{N}_{10}, 2+\mathrm{N}_{18}$ (Table S2, Fig.S2), $3+\mathrm{N}_{9}, 3+\mathrm{N}_{10}, 3+\mathrm{N}_{17}$ (Table S3, Fig.S3), $4+\mathrm{N}_{9}, 4+\mathrm{N}_{10}, 4+\mathrm{N}_{17}$ (Table S4, Fig.S4), and 5+N 10 (Table S5, Fig.S5).

\section{Three-section calls}

\section{Deleted: Ethical statement}

Permission to conduct the study was granted by the Ministry of Science and Technology of the People's Republic of China. The research permit was issued to the Institute of Hydrobiology of the Chinese Academy of Sciences (Permit number: 2011BAG07B05). II

Deleted: Over 16 recording days, a

Deleted: daily 
Calls consisting of three sections included call types $(1-)^{2}+\mathrm{N}_{9},(1-)^{2}+\mathrm{N}_{10},(1-)^{2}+\mathrm{N}_{12}$ (Table S6,

231 Fig.7A and Fig.S6), $1+2+\mathrm{N}_{10}, 1+2+\mathrm{N}_{18}$ (Table S7, Fig.S7), $2+1+\mathrm{N}_{9}, 2+1+\mathrm{N}_{10}$ (Table S8, Fig.S8),

$(2-)^{2}+\mathrm{N}_{10}$ (Table S9, Fig.S9), $3+1+\mathrm{N}_{9}, 3+1+\mathrm{N}_{10}$ (Table S10, Fig.S10), 3+2+N 9 (Table S11, Fig.S11) and $4+1+\mathrm{N}_{10}$ (Table S9, Fig.S9).

\section{Four-section calls}

Calls consisting of four sections included call types $(1-)^{3}+\mathrm{N}_{9},(1-)^{3}+\mathrm{N}_{10},(1-)^{3}+\mathrm{N}_{12}($ Table S12,

236 Fig.7B and Fig.S12), $(1-)^{2}+2+\mathrm{N}_{9},(1-)^{2}+2+\mathrm{N}_{10}$ (Table S13, Fig.S13), $(1-)^{2}+3+\mathrm{N}_{10}($ Table S14,

Fig.S14), $2+(1-)^{2}+\mathrm{N}_{9}, 2+(1-)^{2}+\mathrm{N}_{10}$ (Table S15, Fig.S15), $2+1+2+\mathrm{N}_{9}, 2+1+2+\mathrm{N}_{10}$ (Table S16, Fig.S16) and $3+(1-)^{2}+\mathrm{N}_{9}$ (Table S11, Fig.S11).

\section{Five-section calls}

Calls consisting of five sections included call types $(1-)^{4}+\mathrm{N}_{9},(1-)^{4}+\mathrm{N}_{10},(1-)^{4}+\mathrm{N}_{12}$ (Table S17

Fig.7C and Fig.S17), $(1-)^{3}+2+\mathrm{N}_{10}, \quad(1-)^{3}+3+\mathrm{N}_{10} \quad\left(\right.$ Table S18, Fig.S18), $(1-)^{2}+2+1+\mathrm{N}_{10}$

$(1-)^{2}+2+3+\mathrm{N}_{10}$ (Table S19, Fig.S19), and $2+(1-)^{3}+\mathrm{N}_{10}$ (Table S20, Fig.S20).

\section{Six-section calls}

Calls consisting of six sections included call types $(1-)^{5}+\mathrm{N}_{9},(1-)^{5}+\mathrm{N}_{10}$ (Table S21, Fig.7D and Fig.S21), $(1-)^{4}+2+\mathrm{N}_{10},(1-)^{4}+3+\mathrm{N}_{11}$ (Table S22 and Fig.S22), $(1-)^{3}+2+1+\mathrm{N}_{10}$ (Table S23 and Fig.S23), and $2+(1-)^{4}+\mathrm{N}_{10}$ (Table S20, Fig.S20).

\section{Seven-section calls}

Calls consisting of seven sections included call types (1- $)^{6}+\mathrm{N}_{10}$ (Table S24, Fig.7E and Fig.S24), $(1-)^{5}+2+\mathrm{N}_{10},(1-)^{5}+3+\mathrm{N}_{10}$ (Table S25 and Fig.S25), $(1-)^{4}+2+1+\mathrm{N}_{10}$ (Table S23 and Fig.S23), and $(1-)^{4}+(2-)^{2}+\mathrm{N}_{10}$ (Table S26 and Fig.S24).

\section{Eight-section calls}


and $(1-)^{5}+(2-)^{2}+\mathrm{N}_{10}$ (Table S26 and Fig.S26).

\section{Principal component, discriminant function and hierarchical}

\section{cluster analyses}

The principal component analysis indicated that approximately $81.1 \%$ of the variability is explained by the first four principal components $(39.2 \%$ by principal component $1,18.1 \%$ by principal component $2,13.2 \%$ by principal component 3 , and $10.6 \%$ by principal component 4 ). Principal component 1 was loaded with the $\tau_{-3 \mathrm{~dB}}, \tau_{-10 \mathrm{~dB}}, \mathrm{f}_{\mathrm{c}}, \mathrm{BW} \mathrm{W}_{\mathrm{rms}}$ and $\mathrm{Q}$ parameters. Principal component 2 was loaded with $\mathrm{f}_{\mathrm{p}}$. The third component describes the temporal parameter of the IPPI, and the fourth component describes the temporal parameters of $\tau_{-10 \mathrm{~dB}}$ and the IPPI. The validity of our call types was confirmed using a canonical discriminant function that grouped $\mathrm{N}_{17}, 1+\mathrm{N}_{19}$, $2+\mathrm{N}_{18}$ and $3+\mathrm{N}_{17}$ (Fig. $\left.8 \mathrm{~A}\right)$. Call types with an analyzed number greater than five were extracted for further discriminant and cluster analyses and 31 call types meet the requiment and account for 93.82\% of all analyzed calls (Fig.S27). Hierarchical clustering using a between-groups linkage method that measures the squared Euclidean distance automatically grouped the 31 extracted call types into five clusters. The $\mathrm{N}_{17}, 1+\mathrm{N}_{19}, 2+\mathrm{N}_{18}$ and $3+\mathrm{N}_{17}$ call types were grouped into one cluster, and ${ }^{i} \mathrm{~N}_{13}$ and ${ }^{i} \mathrm{~N}_{15}$ were grouped together (Fig. $\underline{\text { 8B). Most of the call types with an IPPI median of }}$ $10 \mathrm{~ms}$ were grouped together, and those with an IPPI median of $9 \mathrm{~ms}$ were grouped together (Fig. $\underline{8 \mathrm{~B}) .}$

\section{Call occurrence patterns}

Almost all call types with median IPPIs of 9 ms for the last section (i.e., call types with median IPPIs of 9 ms except the $\mathrm{N}_{9}$ call type) were only observed from June 18-20, 2014 (Fig. 9). Most of 
the call types with median IPPIs of $10 \mathrm{~ms}$ for the last section $(88 \%, 29$ out of 33$)$, except $1+\mathrm{N}_{10}$

$(1-)^{2}+\mathrm{N}_{10}, 1+2+\mathrm{N}_{10}$, and $(1-)^{3}+\mathrm{N}_{10}$, were only observed from May 26-June 4 and June 21-22, 2014

(Fig. 9).

\section{Characteristics of call trains}

Of the 52 extracted call trains, the estimated inter-call interval was $1.88 \pm 0.39 \mathrm{~ms}$ (median $\pm \mathrm{QD}$;

P5-P95:1.05-3.04 ms, n=278).

\section{Discussion}

Fish sonic muscles are the fastest-contracting vertebrate muscles (Rome \& Lindstedt 1998). Many soniferous fishes produce species-specific sounds by driving their swim bladders with the highly specialized sonic muscles during courtship to aggregate males and females and facilitate successful mating, especially at night and/or in highly turbid water (Fine \& Parmentier 2015; Tavolga 1964). The spawning-related sounds produced by soniferous fishes have been widely used to identify the timing of spawning and map the areas where spawning occurs (Locascio \& Mann 2011; Turnure et al. 2015). The sound recording period in our study was during the spawning seasons of a majority of the local fishes because their reproduction behavior was most evident from March through June in the Pearl River Estuary(Sadovy 1998). The spawning activity of the greyfin croaker (Pennahia anea) occurred from March-April to June (Tuuli et al. 2011), the spawning season of the spiny-head croaker (Collichthys lucidus) began in March and lasted until December, and the season for Belanger's croaker (Johnius belangerii) was from April to December (Li et al. 2000a; Sadovy 1998). In the present study, presumably spawning choruses were recorded daily, indicating that the sound recording location is a spawning place for local soniferous fish. The smallest inter-pulsepeak
Deleted: 8 
interval in our study was $8.32 \mathrm{~ms}$, which was longer than and further validated the conservatively defined $8 \mathrm{~ms}$ pulse duration.

In this study, the call types were categorized primarily by their IPPI patterns rather than the IPPI ranges. Although there was some overlap in the range of IPPIs, $\mathrm{N}_{9}$ and $\mathrm{N}_{10}$ (A4 and B4 in Fig. 4 and Fig. S28) and ${ }^{i} \mathrm{~N}_{13}$ and ${ }^{\mathrm{i}} \mathrm{N}_{15}$ (A4 and B4 in Fig. 5) were separated based on the distribution pattern of their IPPIs.

\section{Sound comparison of soniferous fish in the PRE}

The South China Sea, with at least 2321 fish species belonging to 35 orders, 236 families and 822 genera (Ma et al. 2008), has long been recognized as a global center of marine tropical biodiversity (Barber et al. 2000) and is one of the richest areas in China, even globally, in terms of its marine fish diversity (Huang 1994; Ma et al. 2008). More than 834 fish species belonging to 25 orders, 124 families and 390 genera were recorded in the waters near Hong Kong (Ni \& Kwok 1999).

\section{Comparisons with Sciaenid sounds}

Fishes of the family Sciaenidae, which are commonly known as croakers or drums, are some of the most well-studied soniferous fish species, and more than 23 species in this family were recorded in the waters near Hong Kong (Ni \& Kwok 1999).

\section{Voluntary sounds}

In free-ranging conditions, big-snout croaker (J. macrorhynus) can emit voluntary purr signals with the first and the remaining IPPIs averaging $40.1 \mathrm{~ms}$ and $9.7 \mathrm{~ms}$ in the field and $35.3 \mathrm{~ms}$ and $10.4 \mathrm{~ms}$ in a large aquarium, respectively (Table 5) (Lin et al. 2007). These resemble the $1+\mathrm{N}_{10}$ call type in our study (Table 4, Fig. 6A) (note that the IPPI was equal to the summation of the pulse duration and the inter-pulse interval in Lin et al. 2007). In addition, the peak frequency of the pulses 

(mean \pm sd: $1050 \pm 84, \mathrm{~N}=60$ ). Additionally, the voluntary dual-knock signal of big-snout croaker with an average IPPI of $36.7 \mathrm{~ms}$ and $39.4 \mathrm{~ms}$ as recorded in the field and in a large aquarium, respectively (Table 5) (Lin et al. 2007), resembled the 1+1 call type in our study with an IPPI of $40.70 \pm 4.08$ (mean \pm sd) (Table S1, Fig.S1B). These matches were further supported by the fact that the peak frequency of the pulses in the $1+1$ call type (mean \pm sd: $1077.75 \pm 219.58, \mathrm{~N}=126$ ) was close to that of the dual-knock recorded in the field (mean \pm sd: $1133 \pm 119, \mathrm{~N}=40$ ) or a large aquarium (mean \pm sd: $1135 \pm 85, \mathrm{~N}=50$ ).

It is possible that $J$. macrorhynchus might emit dual-knock and purr signals in series and create a multiple section call type, such as one dual knock combined with one purr which may result in a synthetic three section call type of $1+2+\mathrm{N}_{10}$ (time gap between the two signals was equal to $10 \mathrm{~ms}$ ) or a four section call type of $1+1+1+\mathrm{N}_{10}$ (time gap between the two signals was over $20 \mathrm{~ms}$ ). However, both of the synthetic $1+2+\mathrm{N}_{10}$ and $1+1+1+\mathrm{N}_{10}$ signals with the third IPPI ascribed to the first IPPI of the purr signal and averaged at $40.1 \mathrm{~ms}$ (Lin et al., 2007) can't match either the $1+2+\mathrm{N}_{10}$ or the $1+1+1+\mathrm{N}_{10}$ call types in our study, since both of which with the third IPPI of less than $30 \mathrm{~ms}$ (A in Fig.S7 and B in Fig. S12).Belanger's croaker can emit sounds with the first IPPI much longer than subsequent IPPIs, which follow at regular intervals of approximately $20 \mathrm{~ms}$ (Pilleri et al. 1982) and resemble the $1+\mathrm{N}_{19}$ call type in our study, although the first IPPI in Belanger's croaker (approximately $40 \mathrm{~ms}$ ) (Table 5) (Pilleri et al. 1982) was smaller than that in the $1+\mathrm{N}_{19}$ call type (median at $71.36 \mathrm{~ms}$ ) (Table 4, Fig. 6C). Their similarity was further strengthened by the fact that the temporal and frequency characteristics of the signal emitted by Belanger's croaker, which

\section{Deleted: s}

\section{Deleted:}

Deleted: ed 
consists of 4-14 pulses with a 140-260 ms call duration, a 500-1000 Hz peak frequency and a majority of the energy within the $500-4000 \mathrm{~Hz}$ frequency band (Pilleri et al. 1982), resemble those of the $1+\mathrm{N}_{19}$ call type, which consists of 3-12 pulses with a 97.37-272.85 ms call duration and peak frequency median of approximately $789 \mathrm{~Hz}$ (Table 4).

Sounds from the white croaker (Pennahia argentata) (Ramcharitar et al. 2006; Takemura et al. 1978), southern meagre (Argyrosomus japonicus) (Ueng et al. 2007), yellow drum (Nibea albiflora) (Ramcharitar et al. 2006; Ren et al. 2007; Takemura et al. 1978), Reeve's croaker (N. acuta or Chrysochir aureus) (Ren et al. 2007; Trewavas 1971) and large yellow croaker (Liu et al. 2010; Ren et al. 2007) were also compared. However, these sounds (Table 5) did not match any call types in our study based on their temporal and/or frequency characteristics.

Belanger's croaker can also emit long bursts with a peak frequency of 750-1250 Hz (Pilleri et al. 1982), and a chorus sound of unknown species recorded in Xiamen Harbor of East China Sea from 1981-1982 with sound energy concentrated in the $700-1600 \mathrm{~Hz}$ frequency band and a peak frequency of $1250 \mathrm{~Hz}$ was proposed to be emitted by Belanger's croaker (Zhang et al. 1984). Chorus sounds of the genus Johnius (possibly J. fasciatus or J. amblycephalus) and the genus Pennahia (possibly P. miichthioides) recorded in the Bohai Sea and Yellow Sea from 1989-1990 were also reported. The sounds emitted by the former genus have an average peak frequency of $2000 \mathrm{~Hz}$ and a majority of energy concentrated in the 1000-4000 Hz frequency band, whereas the sounds emitted by the latter genus have an average peak frequency of $400 \mathrm{~Hz}$ and majority of energy concentrated in the 200-800 Hz frequency band (Xu \& Qi 1999). Chorus sounds of the spiny-head croaker were recorded in the South China Sea, with a majority of energy concentrated in the $500-1250 \mathrm{~Hz}$ frequency band and a peak frequency of approximately $1000 \mathrm{~Hz}$ (Qi et al. 1982)._Chorus sounds of 
unknown species recorded in the adjacent waters of Xiamen Harbor of the East China Sea from 1981-1982, with sound energy concentrated in the 700-1600 Hz frequency band and peak frequencies of $800 \mathrm{~Hz}$ and $1000 \mathrm{~Hz}$, were ascribed to the spiny-head croaker (Zhang et al. 1984). However, detailed waveform, spectrum and statistical results for the temporal and frequency characteristics of individual sounds in these choruses were not available, preventing direct comparison with our study.

\section{Disturbance sound}

Sound recorded under disturbance, e.g., under hand-held conditions is possibly not significantly different from those recorded under voluntary conditions and can be employed to match the sound in the field (Lin et al. 2007). In addition, the sound recording region is a hot spot of humpback dolphin (Wang et al. 2015b), the predator of soniferous fish, which may impose a stress for local fish and may trigger them to emit a signal similar to the hand-held disturbance call. Thus, we also compared the disturbance sound of the sciaenid species distributed in our study region, including Belanger's croaker (Mok et al. 2011a), big-snout croaker (Huang 2016; Lin et al. 2007; Mok et al. 2011a),J. distincus, J.amblycephalus and J.sp., sin croaker (J. dussumieri), white croaker, greyfin

\section{Deleted: Sciaenidae} croaker, bighead white croaker (P. macrocephalus), pawak croaker (P. pawak), Reeve's croaker, tiger-toothed croaker (Otolithes ruber), and blackmouth croaker (Atrobucca nibe) (Huang 2016; Mok et al. 2011a; Tsai 2009). However, the temporal and frequency patterns of these signals did not match any call types in our study (Table 5).

\section{Comparison with other soniferous fish families}

Sounds from other soniferous fish families, including cutlassfish (Trichiurus haumela, family: Trichiuridae), elongate ilisha (Ilisha elongata, family: Pristigasteridae) (Ren et al. 2007), sea catfish 
420 2016)

(Arius sp. and A. maculates, family: Ariidae) (Mok et al. 2011a; Ren et al. 2007), pearl perch (Glaucosoma buergeri, family: Glaucosomatidae) (Mok et al. 2011b), bigeye snapper (Priacanthus macracanthus, family: Priacanthidae), trumpeter perch (Pelates quadrilineatus, family: Terapontidae) and javelin grunter (Pomadasys kaakan, family: Haemulidae) (Tsai 2009), were also compared with our call types but did not match any call types in our study in the temporal and spectral characteristics (Table 5).

\section{Comparison with biological sounds from other passive acoustic}

\section{monitoring sites}

The statistical parameters of the eight types of wild fish sounds recorded in seven estuaries of the west coast of Taiwan using passive acoustics were unfortunately not available, which restricted direct comparison (Mok et al. 2011a). However, the general trend of the $1+\mathrm{N}_{10}$ and $1+\mathrm{N}_{12}$ call types in our study resembles their type B signal (Mok et al. 2011a), with the first inter-pulse interval much longer than the following ones that had a non-increasing inter-pulse interval toward the end of the call, and the $\mathrm{N}_{17}$ call type in our study resembles their type E signal (Mok et al. 2011a), with a gradually increasing inter-pulse interval toward the end of the call and the sound energy concentrated in discrete bands. Sounds with much longer second or third inter-pulse intervals, which resemble our $2+\mathrm{N}$ and $3+\mathrm{N}$, respectively, were also observed in the Chosui River in Taiwan (Mok et al. 2011a), but the sound producer was not identified. Four call types from three recording sites on the northwestern coast of Taiwan were recorded, with the call type identical to the purr signal of J. macrorhynus dominated the soundscape and was the most abundance call type of these sites(Huang 2016). The waveform of call type T3 resemble our call types of ${ }^{i} \mathbf{N}_{13}$ and ${ }^{\mathrm{i}} \mathbf{N}_{13}$ (Huang (1) 


\section{Occurrence pattern of call types}

In order to communicate without misinterpreting, messages and to avoid jamming, different species of a fish community will partition the underwater acoustic environment (Ruppé et al. 2015).

In our study, most call types with IPPI medians at $9 \mathrm{~ms}$ and $10 \mathrm{~ms}$ were observed at times that were exclusive from each other, suggesting they might have been produced by different species.

The spotted seatrout (Cynoscion nebulosus) is one of the few sciaenid species that produces as many as four types of call (Mok \& Gilmore 1983). It is likely that most sciaenid species have fewer call types. Of all the 66 call types recognized in the survey sites, some of the which might come from the same species. According to the result of cluster analysis, five clades were revealed. However, it's still too early to hypothesize that these groups belong to the call repertoire of five species. Additional studies with more controlled conditions, such as in an aquarium or with field recording equipped with a high-definition sonar system will be required to identify the species producing the calls in our study.

\section{Call trains}

Due to the relative simplicity of vocal mechanisms and lack of ability to produce complex calls, fish typically emit sounds with variation in either the temporal and/or frequency patterning (Rice \& Bass 2009). As most of the call types were identified based on the number of sections and the repetition of the anterior section, it is likely that a species might be able to produce several call types by varying the anterior sections of the call as a response to the variable external stimuli. Additionally, the temporal and spectral characteristics of fish signals are involved in information coding and are important parameters for the recognition of sound in fishes (Malavasi et al. 2008; Spanier 1979). In the present study, fish sounds tended to be frequency modulated, e.g., the peak frequency of the
Deleted: the field environment,

Deleted: the

Deleted: a single

Deleted: ier

Deleted: such as the DIDSON Dual-frequency Identification Sonar system, 
pulses within a call were variable (Fig. $2 \mathrm{~F}$ ), and amplitude modulated, e.g., the ${ }^{\mathrm{i}} \mathrm{N}_{13}$ and ${ }^{\mathrm{i}} \mathrm{N}_{15}$ call

types. This is possible because the amplitude of the sound is determined by the swim bladder (Fine et al. 2001; Tavolga 1964) and the dominant frequency of the signal is determined by the sonic muscle twitch duration and the forced response of the swim bladder to sonic muscle contractions rather than the natural resonant frequency of the swim bladder (Connaughton et al. 2002). Additionally, the length of the sonic muscle fibers also related to the body size of the fish(Parmentier \& Fine 2016)

\section{Passive hearing by the dolphin}

The Pearl River Estuary shelters the world's largest known population of Indo-Pacific humpback dolphins (Chen et al. 2010; Jefferson \& Smith 2016; Preen 2004), with an estimated population of 2637 (Coefficient of variation of 19\% to 89\%) (Chen et al. 2010; Jefferson \& Smith 2016). The general preference of this species for estuarine habitats and coastal and shallow water $(<30 \mathrm{~m} \mathrm{depth})$ distribution make it susceptible to the impacts of human activity (Jefferson \& Smith 2016). The current conservation status of the Chinese white dolphin meets the IUCN Red List criteria for classification as Vulnerable; however, the conservation management in a majority of its distribution range is severely inadequate, and the humpback dolphin population in the Pearl River Estuary is declining by $2.5 \%$ annually (Karczmarski et al. 2016).

The humpback dolphin appears to rely almost exclusively on fish for food (Barros et al. 2004; Parra \& Jedensjö 2014). Its prey includes the fish families of Sciaenidae (croakers), Engraulidae (anchovies), Trichiuridae (cutlassfish), Clupeidae (sardines), Ariidae (sea catfish) and Mugilidae (mullets) (Barros et al. 2004; Parra \& Jedensjö 2014). Notably, the majority of these species are soniferous fishes (Banner 1972; Fish \& Mowbray 1970; Ren et al. 2007; Whitehead \& Blaxter 1989).

Deleted: A combination of fisheries entanglement and habitat degradation/loss have contributed to its population decline, along with contributions from pollution and anthropogenic noise disturbances (Jefferson \& Smith 2016; Karczmarski et al. 2016). The magnitude of the threats will increase as land reclamation and sewage discharge continue to expand in the future in addition to the rapid local industrialization. Thus, concerns regarding the conservation of the local humpback dolphin population are increasing. 
The top three most important and frequent prey of humpback dolphins in the Pearl River Estuary are the brackish water species of croaker (Johnius sp.), spiny-head croaker (C. lucidus), and anchovies (Thryssa spp., T. dussumieri and/or T. kammalensis) (Barros et al. 2004). The former two are soniferous fishes (Ren et al. 2007), and the latter might be capable of making sounds (Whitehead \& Blaxter 1989). Additionally, it has been proposed that dolphins rely heavily on eavesdropping (passive listening) (Barros 1993; de Oliveira Santos et al. 2002) during the search phase of the foraging process (Gannon et al. 2005).

In addition to emitting high-frequency pulsed sounds for echolocation and navigation, humpback dolphins can produce narrow-band, frequency-modulated whistles with a fundamental frequency range of $520-33,000 \mathrm{~Hz}$ (Wang et al. 2013) and apparent source levels of $137.4 \pm 6.9 \mathrm{~dB}$ re $1 \mu \mathrm{Pa}$ in rms (Wang et al. 2016) for communication. The fish sounds recorded in this study, which were characterized by a peak frequency between 500 and $2600 \mathrm{~Hz}$ and a maximum zero-to-peak sound pressure level greater than $164 \mathrm{~dB}$, were well within the frequency range of humpback dolphin whistles. It is highly probable that the fish sounds function as acoustic clues of prey to the dolphin, i.e., the dolphin relies heavily on passive hearing during the search phase of the foraging process. This passive hearing mechanism of the local humpback dolphin is further reinforced by the fact that the brackish water species of $C$. lucidus and tapertail anchovy (Coilia mystus, Family: Engraulidae) were the top two predominant species in the seawater/freshwater mixing zones of the Pearl River Estuary (Zhan 1998), accounting for $89 \%$ and $72 \%$ of the numbers and biomass, respectively, of the whole fish stock in the Pearl River Estuary region (Wang \& Lin 2006). The soniferous fish $C$. lucidus was observed to be the second-most important prey for humpback dolphin, but the nonclear what is meant.

Commented [MLJ1]: This could do with rewriting as its not 


\section{Importance and application}

The high biodiversity of fish fauna in the Pearl River Estuary is a treasure of genetic resources

devastating. Historically poor management and overfishing of wild stocks of the large yellow

and marine aquaculture have been applied. However, aquaculture can only supplement, rather than substitute for, wild fisheries (Goldburg \& Naylor 2005). No evidence of recovery in the wild stock of large yellow croaker has been observed, and its genetic diversity continues to decrease (Liu \& Sadovy 2008). Similar lessons can be learned from the Atlantic salmon (Salmo salar) (Goldburg \& environmental impact assessment must be based upon a good understanding of the local biodiversity, the baseline data of suspected fish sounds in our study can facilitate the evaluation of the impacts from various infrastructure projects on local aquatic environments by comparing the baseline to post-construction and/or post-mitigation effort data. Additionally, there is a large body of evidence that the distribution pattern of marine mammals tends to be correlated with the spatial-temporal variability of their prey (Benoit-Bird \& Au 2003; Wang et al. 2015a; Wang et al. 2014a); this correlation was also proposed for the vulnerable local humpback dolphin (Wang et al. 2015b), and the fine-scale distribution pattern of soniferous fishes can aid in the conservation of these

Commented [ML]2]: This a bit vague.

Commented [ML3]: Reference illustrating the collapse.

Commented [ML]4]: You have made this point already keep the focus on the the main theme of the paper.

Deleted: Given the sharp declines in fish stocks, especially of the larger species of croakers owing to overfishing in the Pearl River Estuary, and given that fishing pressure is still high and may be even higher in the future, management activities such as more effective fishing moratoriums should be applied to protect the remaining croakers and other fisheries during the spawning season, especially at their spawning grounds. 


\section{Conclusion}

Using passive acoustic monitoring, the ambient biological sounds in the Pearl River Estuary were

recorded and analyzed. In addition to single pulse, the sounds tend to possess a pulse train structure

with a peak frequency between 500 and $2600 \mathrm{~Hz}$ and most of the energy below $4000 \mathrm{~Hz}$. Sixty-six

call types were identified based on the number of sections, temporal characteristics and amplitude

modulation patterns. Most of the call types with IPPI medians at $9 \mathrm{~ms}$ and those with medians at 10

ms were observed at times that were exclusive from each other, suggesting that they might be produced by different species. A literature review suggested that the $1+1$ and $1+\mathrm{N}_{10}$ call types might

belong to big-snout croaker ( $J$. macrorhynus) and $1+\mathrm{N}_{19}$ might be produced by Belanger's croaker $(J$

belangerii). The baseline data of suspected fish sounds in our study can facilitate the evaluation of the impact from various infrastructure projects on the local aquatic environments by comparing the baseline to post-construction and/or post-mitigation effort data, and the fine-scale distribution pattern of soniferous fishes can aid in the conservation of the local vulnerable humpback dolphins.

\section{Acknowledgments}

We gratefully acknowledge Wenjun Xu of the Ningbo No.2 High School in Zhejiang Province for her statistical assistance. Special thanks are also extended to Andrew J. Read of the Duke University Marine Laboratory for his helpful discussion about this study. 


\section{References}

Au WWL. 1993. The sonar of dolphins. New York: Springer-Verlag.

Au WWL. 2004. Echolocation signals of wild dolphins. Acoustical Physics 50:454-462.

Banner A. 1972. Use of sound in predation by young lemon sharks, Negaprion brevirostris (Poey). Bulletin of Marine Science 22:251-283.

Barber PH, Palumbi SR, Erdmann MV, and Moosa MK. 2000. Biogeography: a marine Wallace's line? Nature 406:692-693.

Barros NB. 1993. Feeding ecology and foraging strategies of bottlenose dolphins on the central east coast of Florida Ph.D.thesis. University of Miami.

Barros NB, Jefferson TA, and Parsons ECM. 2004. Feeding habits of Indo-Pacific humpback dolphins (Sousa chinensis) stranded in Hong Kong. Aquatic Mammals 30: 179-188.

Benoit-Bird KJ, and Au WW. 2003. Prey dynamics affect foraging by a pelagic predator (Stenella longirostris) over a range of spatial and temporal scales. Behavioral Ecology and Sociobiology 53:364-373.

Chen T, Hung SK, Qiu YS, Jia XP, and Jefferson TA. 2010. Distribution, abundance, and individual movements of Indo-Pacific humpback dolphins (Sousa chinensis) in the Pearl River Estuary, China. Mammalia 74:117-125. 10.1515/Mamm.2010.024

Connaughton MA, Fine ML, and Taylor MH. 2002. Weakfish sonic muscle: influence of size, temperature and season. Journal of experimental biology 205:2183-2188.

de Oliveira Santos MC, Rosso S, dos Santos RA, Lucato S, and Bassoi M. 2002. Insights on small cetacean feeding habits in southeastern Brazil. Aquatic Mammals 28:38-45.

Fine ML, Malloy KL, King C, Mitchell SL, and Cameron TM. 2001. Movement and sound generation by the toadfish swimbladder. Journal of comparative Physiology A 187:371-379.

Fine ML, and Parmentier E. 2015. Mechanisms of Fish Sound Production. In: Ladich F, ed. Sound Communication in Fishes: Springer Vienna, 77-126.

Fish MP, and Mowbray WH. 1970. Sound of western North Atlantic fishes. Baltimore and London: The Johns Hopkins Press.

Gannon DP, Barros NB, Nowacek DP, Read AJ, Waples DM, and Wells RS. 2005. Prey detection by bottlenose dolphins, Tursiops truncatus: an experimental test of the passive listening hypothesis. Animal Behaviour 69:709-720. http://dx.doi.org/10.1016/j.anbehav.2004.06.020

Goldburg R, and Naylor R. 2005. Future seascapes, fishing, and fish farming. Frontiers in Ecology and the Environment 3:21-28. 10.1890/1540-9295(2005)003[0021:FSFAFF]2.0.CO;2

Ha SJ. 1973. Aspects of sound communication in the damselfish Eupomacentrus partitus Ph.D. Thesis. University of Miami.

Hawkins A, and Amorim MC. 2000. Spawning Sounds of the Male Haddock, Melanogrammus aeglefinus. Environmental Biology of Fishes 59:29-41. 10.1023/A:1007615517287

Huang P-W. 2016. Sound characteristics and spatiotemporal variability of sciaenidae in the coastal water of northwestern Taiwan Master thesis. National Dong Hwa University.

Huang ZG. 1994. Marine species and their distributions in China seas. Beijing: China Ocean Press.

Jefferson TA, and Smith BD. 2016. Re-assessment of the Conservation Status of the Indo-Pacific Humpback Dolphin (Sousa chinensis) Using the IUCN Red List Criteria. Advances in Marine Biology: Academic Press, 1-26.

Karczmarski L, Huang S-L, Or CKM, Gui D, Chan SCY, Lin W, Porter L, Wong W-H, Zheng R, Ho Y-W, Chui 
SYS, Tiongson AJC, Mo Y, Chang W-L, Kwok JHW, Tang RWK, Lee ATL, Yiu S-W, Keith M, Gailey G, and Wu Y. 2016. Humpback Dolphins in Hong Kong and the Pearl River Delta: Status, Threats and Conservation Challenges. Advances in Marine Biology: Academic Press, 27-64.

Li Y, Chen G, and Sun D. 2000a. Analysis of the composition of fishes in the Pearl River estuarine waters. Journal of fisheries of china 24:312-317 (in chinese with english abstract).

Li Y, Chen G, and Sun D. 2000b. Analysis of the composition of fishes in the Pearl River estuarine waters. Journal of fisheries of china 24:312-317(in chinese with english abstract).

Lin YC, Mok HK, and Huang BQ. 2007. Sound characteristics of big-snout croaker, Johnius macrorhynus (Sciaenidae). The Journal of the Acoustical Society of America 121:586-593. doi:http://dx.doi.org/10.1121/1.2384844

Liu M, and Sadovy Y. 2008. Profile of a fishery collapse: why mariculture failed to save the large yellow croaker. Fish and Fisheries 9:219-242. 10.1111/j.1467-2979.2008.00278.x

Liu ZW, Xu XM, and Qin LH. 2010. Sound characteristics of the large yellow croaker, Pseudosciaena crocea (Sciaenidae). Technical Acoustics 29:342-343 (in chinese with english abstract).

Locascio JV, and Mann DA. 2011. Diel and seasonal timing of sound production by black drum (Pogonias cromis). Fishery Bulletin 109:327-338.

Ma C, You K, Zhang M, Li F, and Chen D. 2008. A preliminary study on the diversity of fish species and marine fish faunas of the South China Sea. Journal of Ocean University of China 7:210-214. 10.1007/s11802-008-0210-2

Madsen PT, and Wahlberg M. 2007. Recording and quantification of ultrasonic echolocation clicks from free-ranging toothed whales. Deep Sea Research Part I: Oceanographic Research Papers 54:1421-1444. 10.1016/j.dsr.2007.04.020

Malavasi S, Collatuzzo S, and Torricelli P. 2008. Interspecific variation of acoustic signals in Mediterranean gobies (Perciformes, Gobiidae): comparative analysis and evolutionary outlook. Biological Journal of the Linnean Society 93:763-778.

Mann DA, and Lobel PS. 1997. Propagation of damselfish (Pomacentridae) courtship sounds. The Journal of the Acoustical Society of America 101:3783-3791. doi:http://dx.doi.org/10.1121/1.418425

Mok H-K, Lin S-Y, and Tsai K-E. 2011a. Underwater ambient biological noise in the waters on the west coast of Taiwan. Kuroshio Science 5-1:51-57.

Mok H-K, Parmentier E, Chiu K-H, Tsai K-E, Chiu P-H, and Fine M. 2011b. An Intermediate in the evolution of superfast sonic muscles. Frontiers in Zoology 8:31.

Mok Hk, and Gilmore RG. 1983. Analysis of sound production in estuarine aggregations of Pogonias cromis, Bairdiella chrysoura, and Cynoscion nebulosus (Sciaenidae). . Bulletin of the Institute of Zoology, Academia Sinica 22:157-186.

Ni I-H, and Kwok K-Y. 1999. Marine fish fauna in Hong Kong waters. Zoological studies 38:130-152.

Parmentier E, and Fine ML. 2016. Fish Sound Production: Insights. In: Suthers RA, Fitch WT, Fay RR, and Popper AN, eds. Vertebrate sound production and acoustic communication. Switzerland: Springer International Publishing, 19-50.

Parmentier E, Lecchini D, Frederich B, Brie C, and Mann D. 2009. Sound production in four damselfish (Dascyllus) species: phyletic relationships? Biological Journal of the Linnean Society 97:928-940. 10.1111/j.1095-8312.2009.01260.x

Parra GJ, and Jedensjö M. 2014. Stomach contents of Australian snubfin (Orcaella heinsohni) and IndoPacific humpback dolphins (Sousa chinensis). Marine Mammal Science 30:1184-1198. 


\subsection{1/mms.12088}

Pilleri G, Kraus C, and Gihr M. 1982. The ambient noise in the environment of Sousa plumbea and Neophocaena phocaenoides with special reference to the sounds of Johnius belangerii (Pisces, Sciaenidae). Investigations on cetacea 14:95-128.

Preen A. 2004. Distribution, abundance and conservation status of dugongs and dolphins in the southern and western Arabian Gulf. Biological Conservation 118:205-218.

Qi ME, Zhang SZ, and Song ZX. 1982. The sound production of Collichthys aggregation. Oceanologia ET Limnologia Sinica 13:491-495.

Ramcharitar J, Gannon DP, and Popper AN. 2006. Bioacoustics of fishes of the family Sciaenidae (croakers and drums). Transactions of the American Fisheries Society 135:1409-1431.

Ren XM, Gao DZ, Yao YL, Yang F, Liu JF, and Xie FJ. 2007. Occurrence and characteristic of sound in large yellow croaker (Pseudosciaena crocea). Journal of Dalian fisheries university 22:123-128 (in chinese with english abstract).

Rice AN, and Bass AH. 2009. Novel vocal repertoire and paired swimbladders of the three-spined toadfish, Batrachomoeus trispinosus: insights into the diversity of the Batrachoididae. Journa of experimental biology 212:1377-1391.

Rome LC, and Lindstedt SL. 1998. The quest for speed: muscles built for high-frequency contractions. Physiology 13:261-268.

Romesburg C. 2004. Cluster analysis for researchers. Raleigh, USA: Lulu Press.

Ruppé L, Clément G, Herrel A, Ballesta L, Décamps T, Kéver L, and Parmentier E. 2015. Environmental constraints drive the partitioning of the soundscape in fishes. Proceedings of the National Academy of Sciences 112:6092-6097. 10.1073/pnas.1424667112

Sadovy Y. 1998. Patterns of reproduction in marine fishes of Hong Kong and adjacent waters. In: B.Morton, editor. Proceedings of the third international conference on the marine biology of the south China sea, Hong kong. Hongkong: Hong Kong University Press. p 261-273.

Sadovy Y, and Cheung WL. 2003. Near extinction of a highly fecund fish: the one that nearly got away. Fish and Fisheries 4:86-99.

Spanier E. 1979. Aspects of Species Recognition by Sound in Four Species of Damselfishes, Genus Eupomacentrus (Pisces: Pomacentridae). Zeitschrift für Tierpsychologie 51:301-316. 10.1111/j.1439-0310.1979.tb00691.x

Takemura A, Takita T, and Mizue K. 1978. Studies on the underwater sound-VII: Underwater calls of the Japanese marine drum fishes (Sciaenidae). Bulletin of the Japanese Society of Scientific Fisheries (Japan) 44:121-125.

Tavolga WN. 1964. Sonic characteristics and mechanisms in marine fishes. In: Tavolga WN, ed. Marine Bio-acoustics. New York: Pergamon Press, 195-211.

Trewavas E. 1971. The syntypes of the sciaenid Corvina albida Cuvier and the status of Dendrophysa hooghliensis Sinha and Rao and Nibea coibor (nec Hamilton) of Chu, Lo \& Wu. Journal of fish biology 3:453-461.

Tsai K-E. 2009. Study of the acoustic characters of eleven soniferous fish in the western coastal waters of Taiwan Master Master thesis. National Sun Yat-sen University.

Turnure JT, Grothues TM, and Able KW. 2015. Seasonal residency of adult weakfish (Cynoscion regalis) in a small temperate estuary based on acoustic telemetry: a local perspective of a coast wide phenomenon. Environmental Biology of Fishes 98:1207-1221.

Tuuli CD, De Mitcheson YS, and Liu M. 2011. Reproductive biology of the greyfin croaker Pennahia anea 
in the northern South China Sea. Ichthyological research 58:302-309.

Ueng J-P, Huang B-Q, and Mok H-K. 2007. Sexual Differences in the Spawning Sounds of Japanese Croaker, Argyrosomus japonicus (Sciaenidae). Zoological studies 46:103.

Urick RJ. 1983. Principles of underwater sound. New York: McGraw-Hill.

Wall CC, Lembke C, and Mann DA. 2012. Shelf-scale mapping of sound production by fishes in the eastern Gulf of Mexico, using autonomous glider technology. Marine Ecology Progress Series 449:55-64.

Wall CC, Simard P, Lembke C, and Mann DA. 2013. Large-scale passive acoustic monitoring of fish sound production on the West Florida Shelf. Marine Ecology Progress Series 484:173-188. 10.3354/meps10268

Wang D, and Lin SJ. 2006. Spatial and temporal variation of fish community structure in the Pearl River Estuary waters. South china fisheries science 2:37-45(in chinese with english abstract).

Wang Z-T, Akamatsu T, Mei Z-G, Dong L-j, Imaizumi T, Wang K-X, and Wang D. 2015a. Frequent and prolonged nocturnal occupation of port areas by Yangtze finless porpoises (Neophocaena asiaeorientalis): Forced choice for feeding? Integrative zoology 10:122-132. doi:10.1111/17494877.12102

Wang Z-T, Akamatsu T, Wang K-X, and Wang D. 2014a. The diel rhythms of biosonar behavior in the Yangtze finless porpoise (Neophocaena asiaeorientalis asiaeorientalis) in the port of the Yangtze river: The correlation between prey availability and boat traffic. PloS one 9:e97907. 10.1371/journal.pone.0097907

Wang Z-T, Au W, Rendell L, Wang K-X, Wu H-P, Wu Y-P, Liu J-C, Duan G-Q, Cao H-J, and Wang D. 2016. Apparent source levels and active communication space of whistles of free-ranging Indo-Pacific humpback dolphins (Sousa chinensis) in the Pearl River Estuary and Beibu Gulf, China. PeerJ 4:e1695. 10.7717/peerj.1695

Wang Z-T, Fang L, Shi W-J, Wang K-X, and Wang D. 2013. Whistle characteristics of free-ranging IndoPacific humpback dolphins (Sousa chinensis) in Sanniang Bay, China. The Journal of the Acoustical Society of America 133:2479-2489. doi: 10.1121/1.4794390

Wang Z-T, Nachtigall PE, Akamatsu T, Wang K-X, Wu Y-P, Liu J-C, Duan G-Q, Cao H-J, and Wang D. 2015b. Passive acoustic monitoring the diel, lunar, seasonal and tidal patterns in the biosonar activity of the Indo-Pacific humpback dolphins (Sousa chinensis) in the Pearl River Estuary, China. PLOS ONE 10:e0141807. doi: 10.1371/journal.pone.0141807

Wang Z-T, Wu Y-P, Duan G-Q, Cao H-J, Liu J-C, Wang K-X, and Wang D. 2014b. Assessing the underwater acoustics of the world's largest vibration hammer (OCTA-KONG) and its potential effects on the Indo-Pacific humpbacked dolphin (Sousa chinensis). PLOS ONE 9:e110590. doi: 10.1371/journal.pone.0110590

Whitehead PJP, and Blaxter JHS. 1989. Swimbladder form in clupeoid fishes. Zoological Journal of the Linnean Society 97:299-372. 10.1111/j.1096-3642.1989.tb00107.x

Xu LY, and Qi ME. 1999. Noise specctra of two fishes as observed in Bohai sea and Yellow sea. Marine Sciences 4:13-14.

Zar JH. 1999. Biostatistical analysis Upper Saddle River, NJ: Prentice-Hall.

Zhan HG. 1998. Study on fis community structure in the Zhujiang estuary and adjacent waters. Acta Oceanologica Sinica 20:91-97.

Zhang MQ, Shi XQ, Lin XQ, Li W, Ke LY, and Huang XD. 1984. Marine organism chorus obseved in Xiamen Harbor. Acta Oceanologica Sinica 6:10-15 (In chinese). 
Figures and tables

Figure 1 Map of the passive acoustic monitoring area.

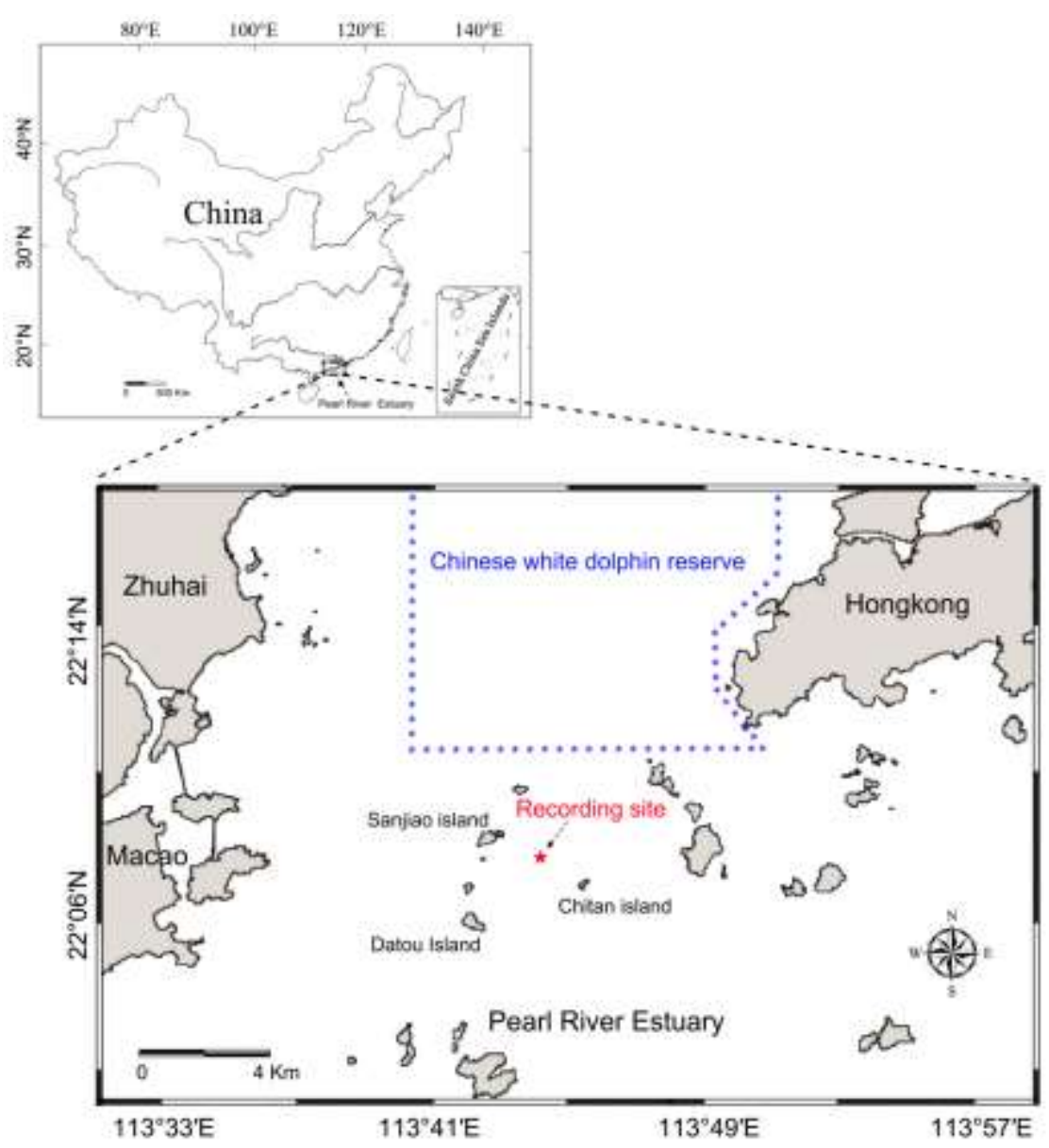

Figure 2 Schematic diagram of the signal analysis. (A) Oscillogram of the raw data with seven

pulses. (B) Pulses detected by the pulse-peak detector. Vertical dashed lines denote the starting

(green), peak (red), and ending (blue) points of a pulse. (C) Close-up of the oscillogram of extracted

8ms pulses showing the fine-scale call structure. (D) The cumulative energy of the extracted pulse, 

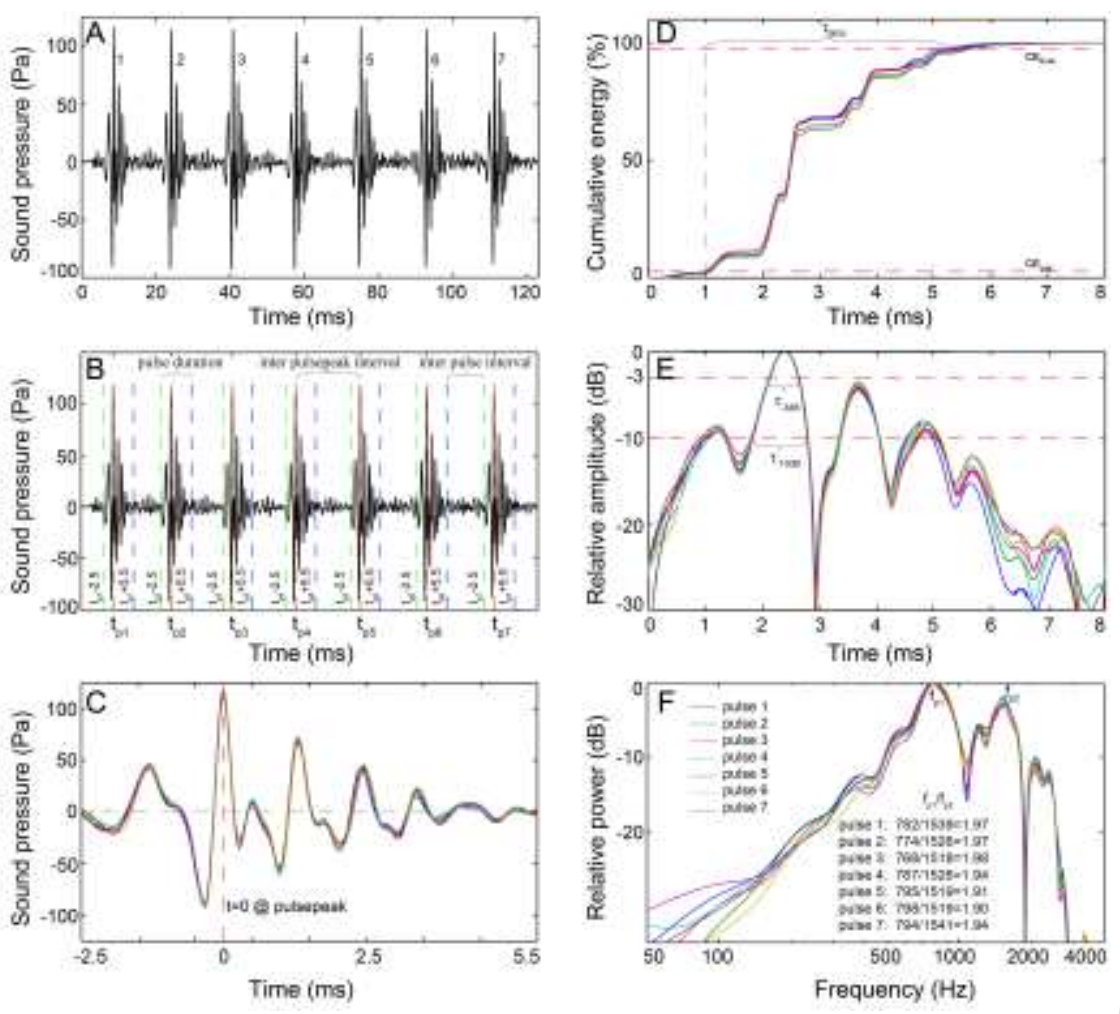

Figure 3 Distribution pattern of the inter-pulsepeak interval (IPPI) for all analyzed calls (A)

and call types with fewer than three pulses (B). The distribution pattern of the pooled IPPIs

peaked at 9, 10, 12,13 and $18 \mathrm{~ms}$ (inset figure in A). Call types with fewer than three pulses,

including a two-pulse call in the $2,1+1,1+\mathrm{N}_{19}$, and ${ }^{\mathrm{i}} \mathrm{N}_{13}$ call types and a three-pulse call in the ${ }^{\mathrm{i}} \mathrm{N}_{13}$,

Formatted: Font: (Default) Times New Roman, Font color:

Text 1, Complex Script Font: Times New Roman, 10.5 pt 
$\mathrm{ms}$ and 10-52 ms
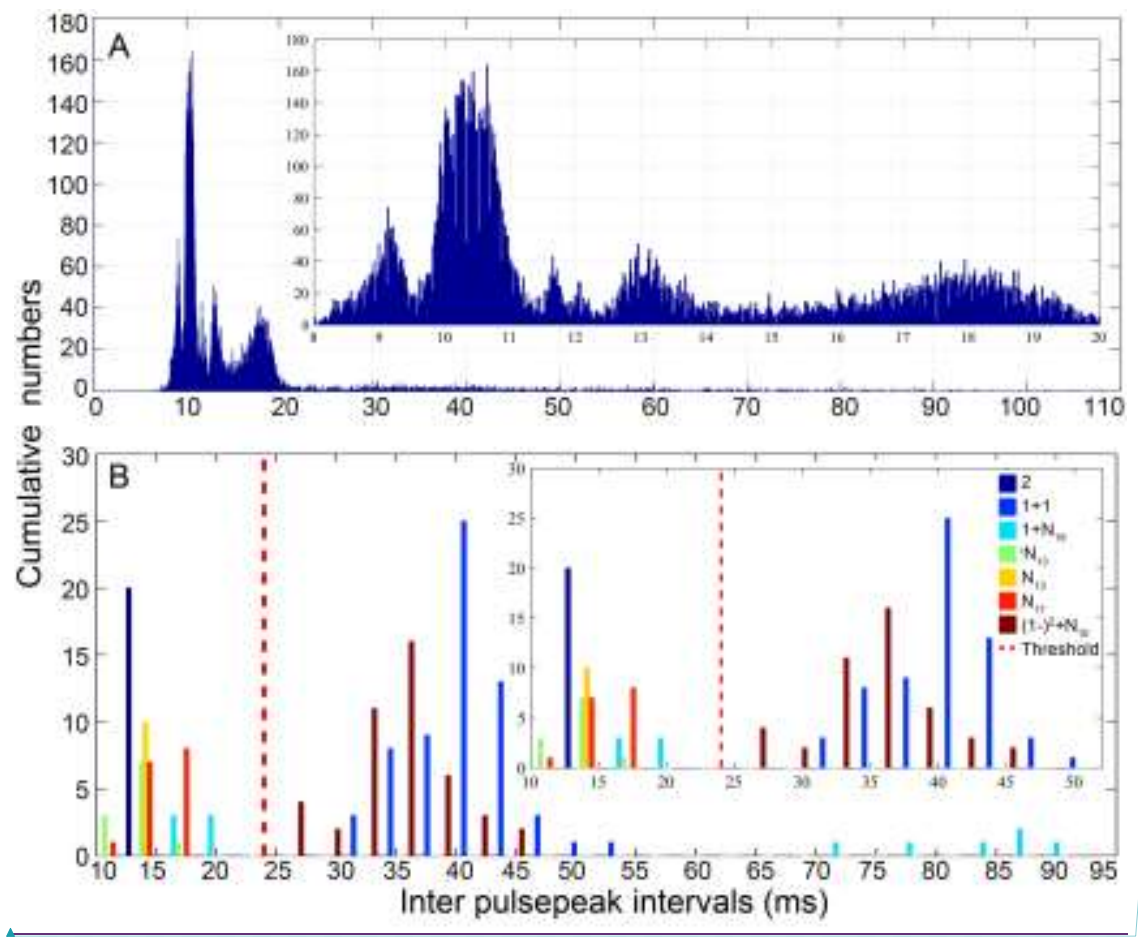

751

the selection of $24 \mathrm{~ms}$, three times the duration of a single $8 \mathrm{~ms}$ pulse, as a threshold for dividing pulses of a call into different sections. The insets show magnified time scales of the IPPI for 8-20

\section{Figure 4 Characteristic of the (A) $\mathbf{N}_{9}$, (B) $\mathbf{N}_{10}$, (C) $\mathbf{N}_{13}$, and (D) $\mathbf{N}_{17}$ call types. Rows 1 and 2 are}

the oscillogram and sonogram, respectively, of a representative signal for each call type. Row 3 is the duration of a call as a function of the number of pulses within the call. Rows 4-7 are the pooled inter-pulsepeak interval, sound pressure level, peak frequency, and center frequency of each pulse versus the order at which it occurs within a call, respectively. For the boxplot, the line inside the box indicates the median value, and the upper and lower box borders are the first and third quartiles, respectively. The length of the box is the interquartile range (IQR). The whiskers extend to the most extreme data within the limit of 1.5 IQRs from the end of the box. Open circles (o) denote mild
Formatted: Font: (Default) Times New Roman, Font color: Text 1, Complex Script Font: Times New Roman, 10.5 pt 

frame, $95 \%$.
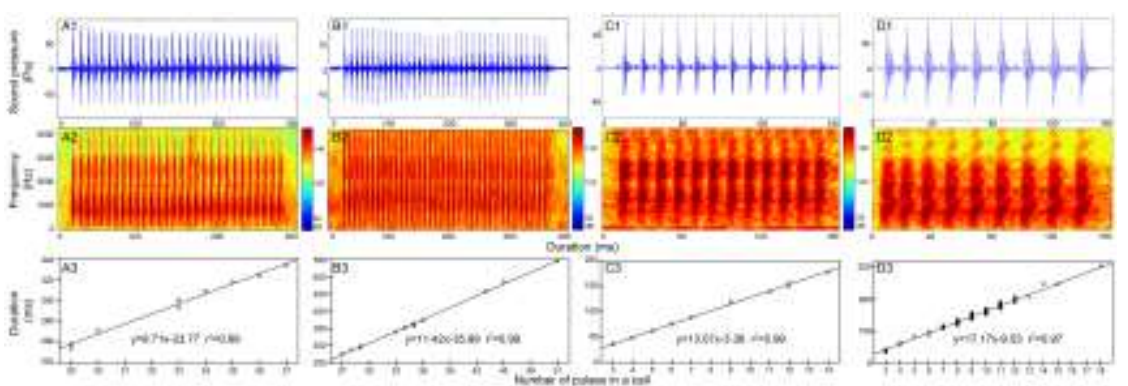

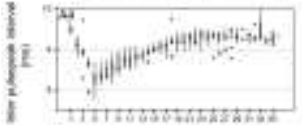
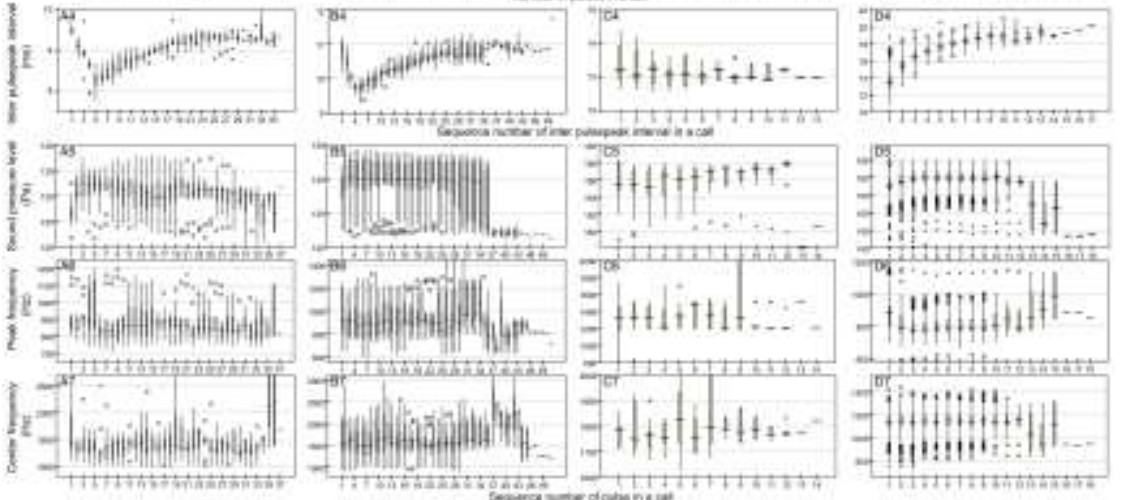

Figure 5 Characteristics of the (A) ${ }^{i} \mathbf{N}_{13}$ and (B) ${ }^{i} \mathbf{N}_{15}$ call types. Rows 1 and 2 are the oscillogram at which it occurs within a call, respectively. 


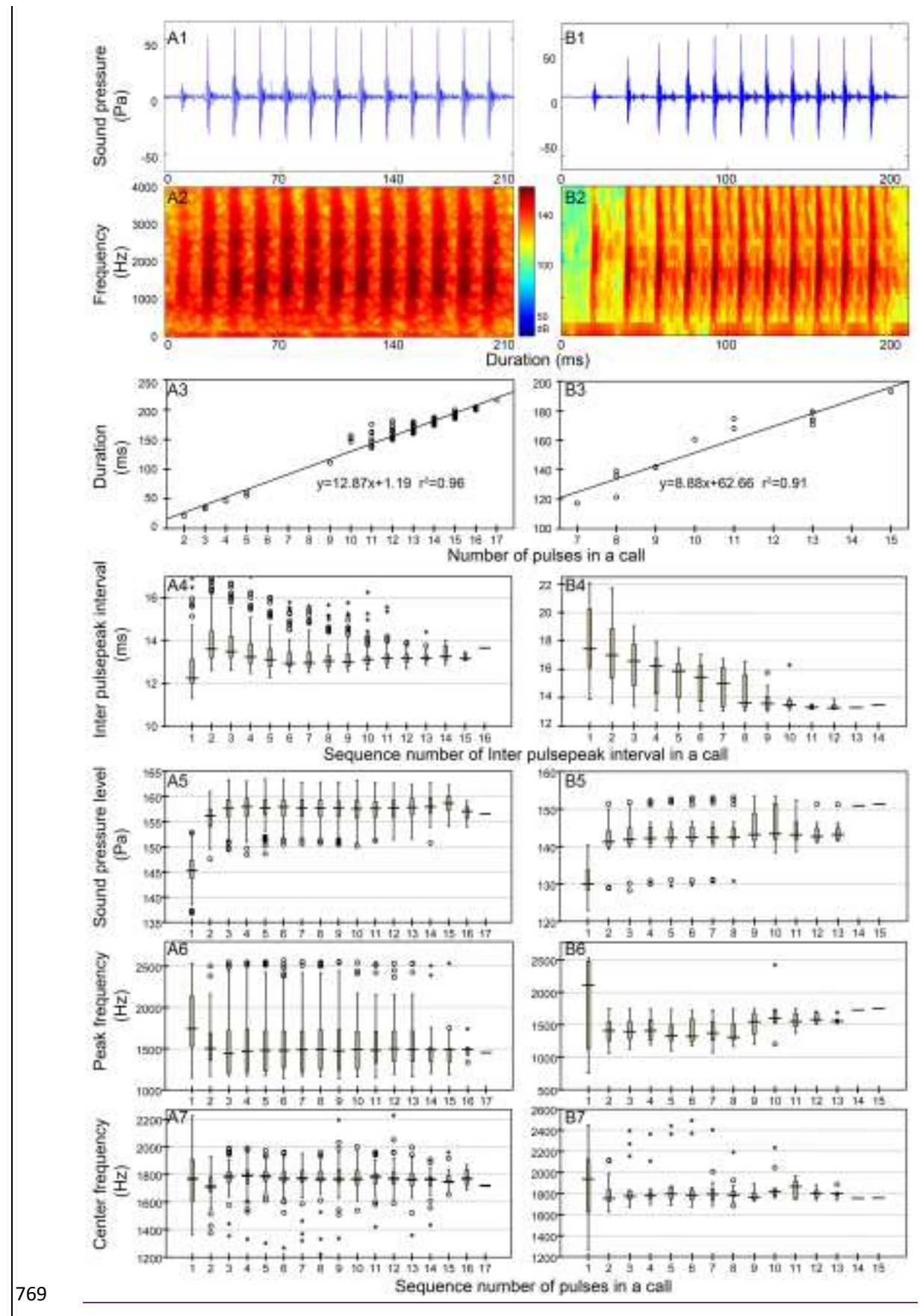

Figure 6 Characteristics of the (A) $1+N_{10}$, (B) $1+N_{12}$ and (C) $1+N_{19}$ call types. Rows 1 and 2 are 
inter-pulsepeak interval, sound pressure level, peak frequency, and center frequency of each pulse

the oscillogram and sonogram, respectively, of a representative signal for each call type. Row 3 is

the duration of a call as a function of the number of pulses within the call. Rows 4-7 are the pooled

versus the order at which it occurs within a call, respectively.
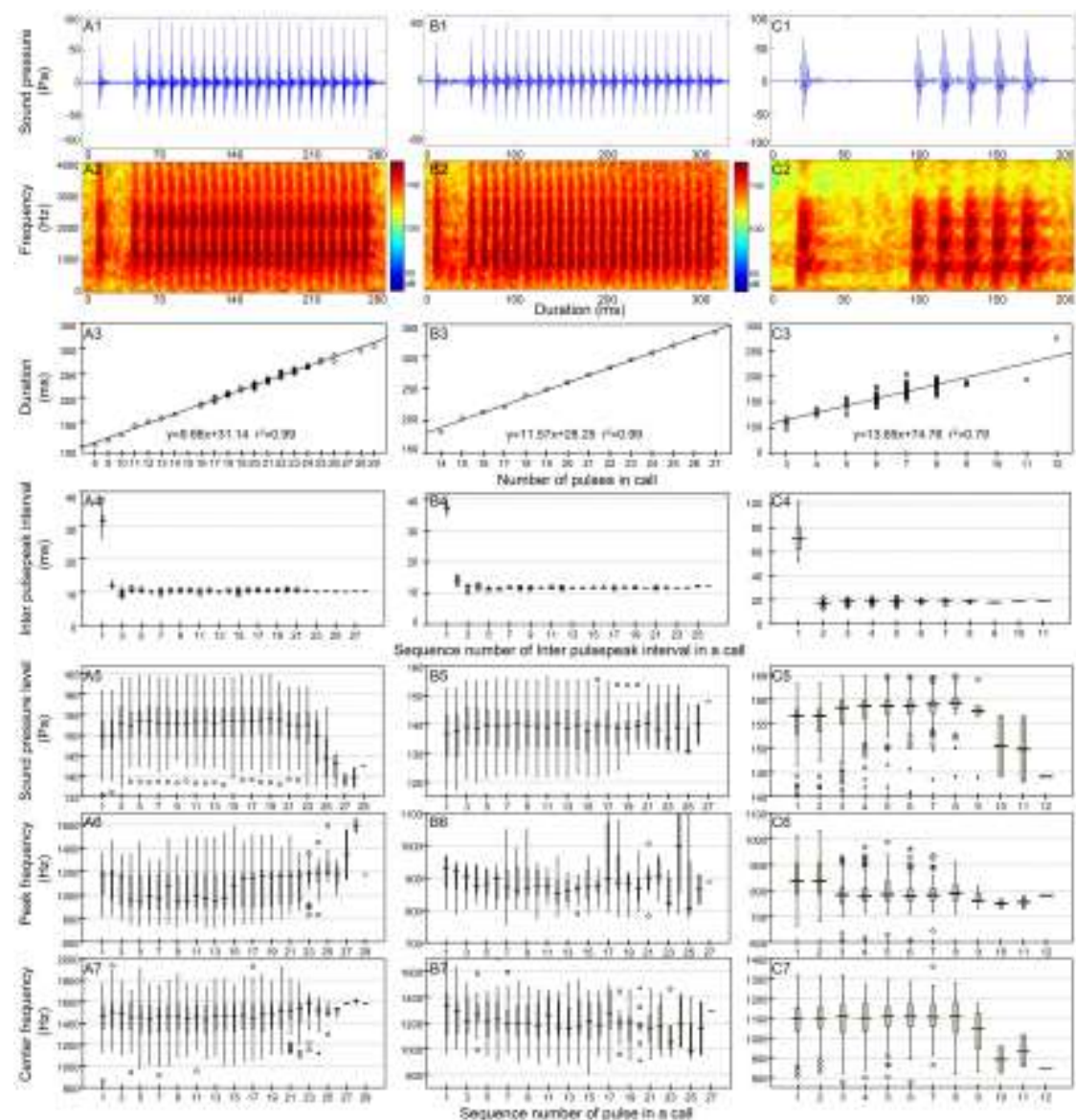

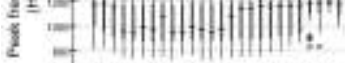

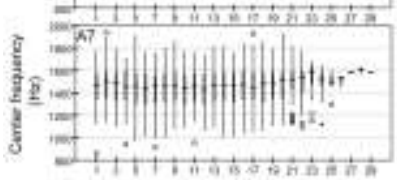
sonimose number dpunt in a cal 

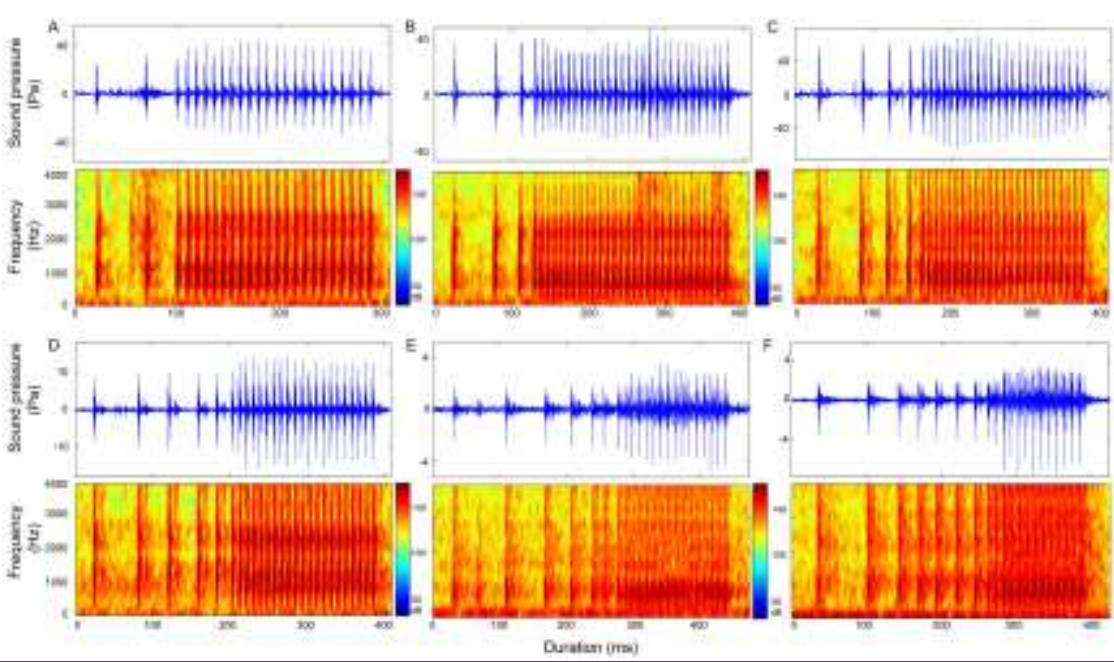

Figure $\_$Scatterplot using the canonical discriminant function (A) and dendrogram using the

hierarchical clustering method (B) of 31 extracted call types. The "Rescaled distance cluster

combine" axis in B shows the distance at which the clusters combine. When creating a dendrogram,

SPSS rescales the actual distance between the cases to fall into a 0-25 unit range; thus, the last

merging step to a one-cluster solution occurs at a distance of 25 .
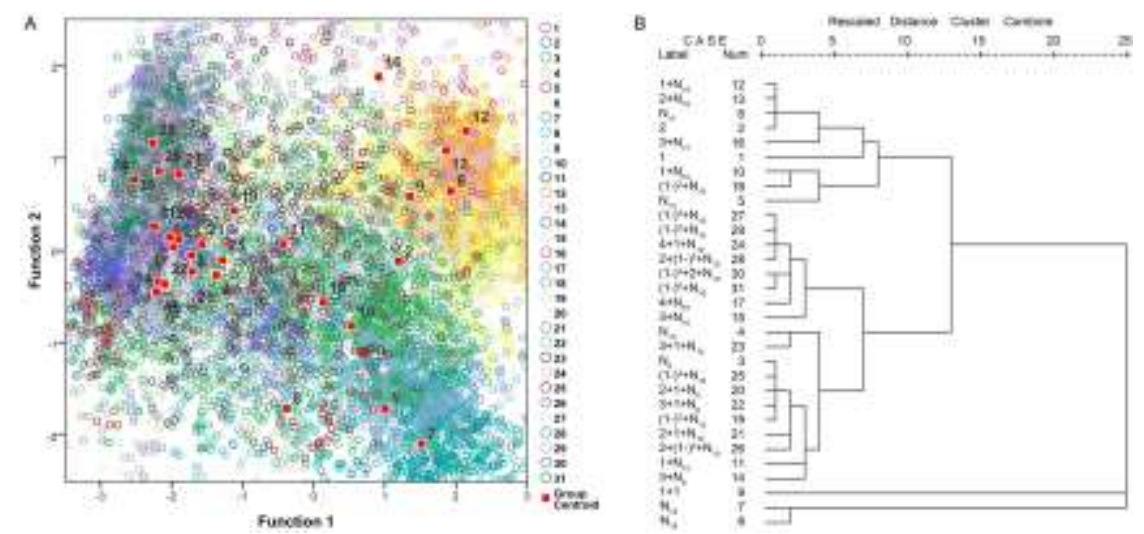

Figure 2 Occurrence pattern of the 66 call types during passive acoustic monitoring periods.

Yellow patches in the matrix indicate the corresponding call types (x-axis) observed on that day (y- 
corresponds to the call type sequence in Table 1.

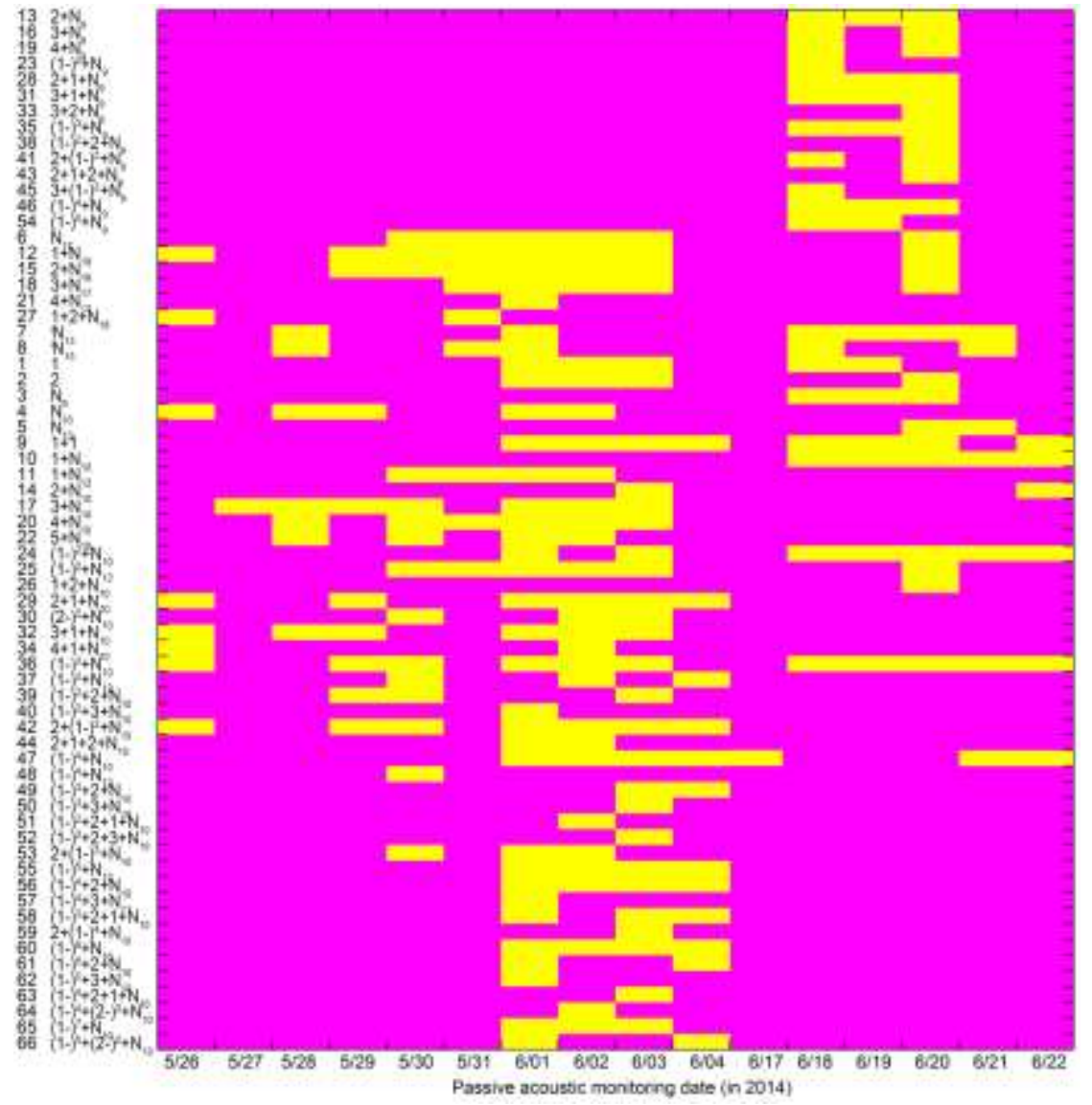


Tables

796 Table 1 Call type classification.

\begin{tabular}{|c|c|c|c|c|}
\hline $\begin{array}{l}\text { Typ } \\
\text { e }\end{array}$ & Call name & No. of sections & Inter-pulsepeak interval (IPPI) pattern & $\begin{array}{l}\text { Observed No. of pulses in } \\
\text { section N }\end{array}$ \\
\hline 1 & 1 & One & & \\
\hline 2 & 2 & One & IPPIs converged at $13 \mathrm{~ms}$ & \\
\hline 3 & $\mathrm{~N}_{9}$ & One & Decreasing then increasing IPPI, median at $9 \mathrm{~ms}$ & 29-30,33-37 \\
\hline 4 & $\mathrm{~N}_{10}$ & One & Decreasing then increasing IPPI, median at $10 \mathrm{~ms}$ & $27-29,33-36,43,45,51$ \\
\hline 5 & $\mathrm{~N}_{13}$ & One & Nearly constant IPPI at $13 \mathrm{~ms}$ & $3-7,9,11,12,14$ \\
\hline 6 & $\mathrm{~N}_{17}$ & One & Increasing IPPI, median at $17 \mathrm{~ms}$ & $3-15,18$ \\
\hline 7 & ${ }^{\mathrm{i}} \mathrm{N}_{13}$ & One & $\begin{array}{l}\text { Increasing, decreasing, then increasing IPPI, } \\
\text { median at } 13 \mathrm{~ms}\end{array}$ & $2-5,9-17$ \\
\hline 8 & ${ }^{\mathrm{i}} \mathrm{N}_{15}$ & One & Decreasing IPPI, median at $15 \mathrm{~ms}$ & $7-11,13,15$ \\
\hline 9 & $1+1$ & Two & IPPI median at $41 \mathrm{~ms}$ & \\
\hline 10 & $1+\mathrm{N}_{10}$ & Two & Nearly constant IPPI, median at $10 \mathrm{~ms}$ & $7-13,15-25,27,28$ \\
\hline 11 & $1+\mathrm{N}_{12}$ & Two & Nearly constant IPPI, median at $12 \mathrm{~ms}$ & $13-26$ \\
\hline 12 & $1+\mathrm{N}_{19}$ & Two & Increasing IPPI, median at $19 \mathrm{~ms}$ & $2-8,10,11$ \\
\hline 13 & $2+\mathrm{N}_{9}$ & Two & Near constant IPPI, median at $9 \mathrm{~ms}$ & $23,25,27,28,30$ \\
\hline 14 & $2+\mathrm{N}_{10}$ & Two & Near constant IPPI, median at $10 \mathrm{~ms}$ & $19,26,27$ \\
\hline 15 & $2+\mathrm{N}_{18}$ & Two & Increasing IPPI, median at $18 \mathrm{~ms}$ & $3-8,10$ \\
\hline 16 & $3+\mathrm{N}_{9}$ & Two & Near constant IPPI, median at $9 \mathrm{~ms}$ & $24-26,29,30$ \\
\hline 17 & $3+\mathrm{N}_{10}$ & Two & Near constant IPPI, median at $10 \mathrm{~ms}$ & $\begin{array}{l}3-11,24-25,27-34,37- \\
39,44\end{array}$ \\
\hline 18 & $3+\mathrm{N}_{17}$ & Two & Increasing IPPI, median at $17 \mathrm{~ms}$ & $4-7$ \\
\hline 19 & $4+\mathrm{N}_{9}$ & Two & Near constant IPPI, median at $9 \mathrm{~ms}$ & $25-27,31$ \\
\hline 20 & $4+\mathrm{N}_{10}$ & Two & Near constant IPPI, median at $10 \mathrm{~ms}$ & $\begin{array}{l}3-7,15,25,28,30- \\
31,33,35,36\end{array}$ \\
\hline 21 & $4+\mathrm{N}_{17}$ & Two & Increasing IPPI, median at $17 \mathrm{~ms}$ & 6 \\
\hline 22 & $5+\mathrm{N}_{10}$ & Two & Nearly constant IPPI, median at $10 \mathrm{~ms}$ & $3-5,7$ \\
\hline 23 & $(1-)^{2}+\mathrm{N}_{9}$ & Three & Nearly constant IPPI, median at $9 \mathrm{~ms}$ & $19,22,23$ \\
\hline 24 & $(1-)^{2}+\mathrm{N}_{10}$ & Three & Nearly constant IPPI, median at $10 \mathrm{~ms}$ & $2,9-24,29,30$ \\
\hline 25 & $(1-)^{2}+\mathrm{N}_{12}$ & Three & Nearly constant IPPI, median at $12 \mathrm{~ms}$ & $6-11,13-15,19-21$ \\
\hline 26 & $1+2+\mathrm{N}_{10}$ & Three & Nearly constant IPPI, median at $10 \mathrm{~ms}$ & 16 \\
\hline 27 & $1+2+\mathrm{N}_{18}$ & Three & Nearly constant IPPI, median at $18 \mathrm{~ms}$ & 5,7 \\
\hline 28 & $2+1+\mathrm{N}_{9}$ & Three & Nearly constant IPPI, median at $9 \mathrm{~ms}$ & $21,23-25,28,29,31,32$ \\
\hline 29 & $2+1+\mathrm{N}_{10}$ & Three & Nearly constant IPPI, median at $10 \mathrm{~ms}$ & $23,25-28,30,32,34,35,40$ \\
\hline 30 & $(2-)^{2}+\mathrm{N}_{10}$ & Three & Nearly constant IPPI, median at $10 \mathrm{~ms}$ & 23,26 \\
\hline 31 & $3+1+\mathrm{N}_{9}$ & Three & Nearly constant IPPI, median at $9 \mathrm{~ms}$ & $23-25,27,30-32,34$ \\
\hline 32 & $3+1+\mathrm{N}_{10}$ & Three & Nearly constant IPPI, median at $10 \mathrm{~ms}$ & $27-31,33-35,37$ \\
\hline 33 & $3+2+\mathrm{N}_{9}$ & Three & Nearly constant IPPI, median at $9 \mathrm{~ms}$ & 26 \\
\hline 34 & $4+1+\mathrm{N}_{10}$ & Three & Nearly constant IPPI, median at $10 \mathrm{~ms}$ & $21,29-31,33$ \\
\hline 35 & $(1-)^{3}+\mathrm{N}_{9}$ & Four & Nearly constant IPPI, median at $9 \mathrm{~ms}$ & $18,21,26,29$ \\
\hline
\end{tabular}




\begin{tabular}{|c|c|c|c|c|}
\hline 36 & $(1-)^{3}+\mathrm{N}_{10}$ & Four & Nearly constant IPPI, median at $10 \mathrm{~ms}$ & $\begin{array}{l}1,9-14,16,17,19,23- \\
25,27-29,31,33\end{array}$ \\
\hline 37 & $(1-)^{3}+\mathrm{N}_{12}$ & Four & Nearly constant IPPIs, median at $12 \mathrm{~ms}$ & $8,10,13$ \\
\hline 38 & $(1-)^{2}+2+\mathrm{N}_{9}$ & Four & Nearly constant IPPI, median at $9 \mathrm{~ms}$ & 26,29 \\
\hline 39 & $(1-)^{2}+2+\mathrm{N}_{10}$ & Four & Nearly constant IPPI, median at $10 \mathrm{~ms}$ & $20,21,29$ \\
\hline 40 & $(1-)^{2}+3+\mathrm{N}_{10}$ & Four & Nearly constant IPPI, median at $10 \mathrm{~ms}$ & 18 \\
\hline 41 & $2+(1-)^{2}+\mathrm{N}_{9}$ & Four & Nearly constant IPPI, median at $9 \mathrm{~ms}$ & 22,23 \\
\hline 42 & $2+(1-)^{2}+\mathrm{N}_{10}$ & Four & Nearly constant IPPI, median at $10 \mathrm{~ms}$ & $20-24,26-33,36$ \\
\hline 43 & $2+1+2+\mathrm{N}_{9}$ & Four & Nearly constant IPPI, median at $9 \mathrm{~ms}$ & 28 \\
\hline 44 & $2+1+2+\mathrm{N}_{10}$ & Four & Nearly constant IPPI, median at $10 \mathrm{~ms}$ & $22,25,30$ \\
\hline 45 & $3+(1-)^{2}+\mathrm{N}_{9}$ & Four & Nearly constant IPPI, median at $9 \mathrm{~ms}$ & 25 \\
\hline 46 & $(1-)^{4}+\mathrm{N}_{9}$ & Five & Nearly constant IPPI, median at $9 \mathrm{~ms}$ & $15,18,23,24$ \\
\hline 47 & $(1-)^{4}+\mathrm{N}_{10}$ & Five & Nearly constant IPPI, median at $10 \mathrm{~ms}$ & $1,6,7,11,13,16-25,27,28$ \\
\hline 48 & $(1-)^{4}+\mathrm{N}_{12}$ & Five & Nearly constant IPPI, median at $12 \mathrm{~ms}$ & 11 \\
\hline 49 & $(1-)^{3}+2+\mathrm{N}_{10}$ & Five & Nearly constant IPPI, median at $10 \mathrm{~ms}$ & 20,21 \\
\hline 50 & $(1-)^{3}+3+\mathrm{N}_{10}$ & Five & Nearly constant IPPI, median at $10 \mathrm{~ms}$ & 17 \\
\hline 51 & $(1-)^{2}+2+1+\mathrm{N}_{10}$ & Five & Nearly constant IPPI, median at $10 \mathrm{~ms}$ & 26 \\
\hline 52 & $(1-)^{2}+2+3+\mathrm{N}_{10}$ & Five & Nearly constant IPPI, median at $10 \mathrm{~ms}$ & 14 \\
\hline 53 & $2+(1-)^{3}+\mathrm{N}_{10}$ & Five & Nearly constant IPPI, median at $10 \mathrm{~ms}$ & $23-25,27,28,32$ \\
\hline 54 & $(1-)^{5}+\mathrm{N}_{9}$ & Six & Nearly constant IPPI, median at $9 \mathrm{~ms}$ & 17,21 \\
\hline 55 & $(1-)^{5}+\mathrm{N}_{10}$ & Six & Nearly constant IPPI, median at $10 \mathrm{~ms}$ & $1,16-23,26$ \\
\hline 56 & $(1-)^{4}+2+\mathrm{N}_{10}$ & Six & Nearly constant IPPI, median at $10 \mathrm{~ms}$ & $15,18-20,28$ \\
\hline 57 & $(1-)^{4}+3+\mathrm{N}_{11}$ & Six & Nearly constant IPPI, median at $11 \mathrm{~ms}$ & 11 \\
\hline 58 & $(1-)^{3}+2+1+\mathrm{N}_{10}$ & Six & Nearly constant IPPI, median at $10 \mathrm{~ms}$ & 16,18 \\
\hline 59 & $2+(1-)^{4}+\mathrm{N}_{10}$ & Six & Nearly constant IPPI, median at $10 \mathrm{~ms}$ & 22 \\
\hline 60 & $(1-)^{6}+\mathrm{N}_{10}$ & Seven & Nearly constant IPPI, median at $10 \mathrm{~ms}$ & $14-17,19,20,24$ \\
\hline 61 & $(1-)^{5}+2+\mathrm{N}_{10}$ & Seven & Nearly constant IPPI, median at $10 \mathrm{~ms}$ & $16-18$ \\
\hline 62 & $(1-)^{5}+3+\mathrm{N}_{10}$ & Seven & Nearly constant IPPI, median at $10 \mathrm{~ms}$ & 16 \\
\hline 63 & $(1-)^{4}+2+1+\mathrm{N}_{10}$ & Seven & Nearly constant IPPI, median at $10 \mathrm{~ms}$ & 16 \\
\hline 64 & $\begin{array}{l}(1-)^{4}+(2-)^{2}+\mathrm{N}_{1} \\
0\end{array}$ & Seven & Nearly constant IPPI, median at $10 \mathrm{~ms}$ & 20 \\
\hline 65 & $(1-)^{7}+\mathrm{N}_{10}$ & Eight & Nearly constant IPPI, median at $10 \mathrm{~ms}$ & $11,13,14,19,21$ \\
\hline 66 & $\begin{array}{l}(1-)^{5}+(2-)^{2}+\mathrm{N}_{1} \\
0\end{array}$ & Eight & Nearly constant IPPI, median at $10 \mathrm{~ms}$ & 9,15 \\
\hline
\end{tabular}

797 For each signal, pulses with an inter-pulsepeak interval (IPPI) greater than 1.5 times the median

799 pulses, pulses with an IPPI greater than $24 \mathrm{~ms}$ (three times the duration of a single pulse) were

800 further grouped into different sections. In the call name column, ' + ' is used to separate different

801 sections of a call; the number denotes the number of pulses in that section; '(1-)' and '(2-)' denote 

number of repeats in the repeating section; ' $N$ ' denotes the last section of a call that varied in the number of pulses; the digital subscripts denote the median IPPIs of the last portion of the call; the subscript i denotes calls with a zero-to-peak sound pressure level of the first pulse approximately $10 \mathrm{~dB}$ weaker than that of the remainder within the call. For call types with more than one portion, the IPPI pattern of the last section is given.

Table 2 Descriptive statistics of sonic parameters of the $N_{9}, N_{10}, N_{13}$, and $N_{17}$ call types.

\begin{tabular}{|c|c|c|c|c|c|c|c|c|c|c|c|c|c|c|c|c|}
\hline & & Dur & IPPI & $\tau_{95 \%}$ & $\tau_{-3 \mathrm{~dB}}$ & $\begin{array}{l}\tau . \\
10 \mathrm{~dB}\end{array}$ & $\mathrm{f}_{\mathrm{p}}$ & $f_{c}$ & $\mathrm{BW}_{\mathrm{rms}}$ & Q & $\mathrm{SPL}_{2 \mathrm{p}}$ & SPL $_{\text {rms }}$ & EFD & N1 & $\mathrm{N} 2$ & N3 \\
\hline \multirow[t]{4}{*}{ N9 } & P50 & 300.30 & 9.09 & 3.22 & 0.31 & 0.36 & 856 & 1366 & 1228 & 1.14 & 130.99 & 122.81 & 147.51 & 9 & 287 & 296 \\
\hline & QD & 28.03 & 0.25 & 0.48 & 0.10 & 0.21 & 59 & 153 & 557 & 0.32 & 2.50 & 3.34 & 2.97 & & & \\
\hline & P5 & 253.39 & 8.32 & 2.42 & 0.15 & 0.16 & 747 & 1015 & 679 & 0.48 & 122.99 & 112.08 & 139.48 & & & \\
\hline & P95 & 334.04 & 9.49 & 6.49 & 1.24 & 1.53 & 1144 & 2273 & 4709 & 1.62 & 136.98 & 128.21 & 152.82 & & & \\
\hline \multirow[t]{4}{*}{$\mathrm{N}_{10}$} & P50 & 356.94 & 10.50 & 4.35 & 0.21 & 1.16 & 903 & 1580 & 1222 & 1.27 & 139.67 & 128.22 & 154.66 & 13 & 448 & 461 \\
\hline & QD & 59.78 & 0.29 & 1.51 & 0.11 & 0.48 & 113 & 289 & 525 & 0.31 & 9.20 & 10.27 & 9.09 & & & \\
\hline & P5 & 275.72 & 9.73 & 2.93 & 0.11 & 0.15 & 667 & 1024 & 772 & 0.62 & 123.93 & 110.66 & 138.54 & & & \\
\hline & P95 & 544.98 & 11.07 & 7.39 & 0.43 & 1.72 & 1274 & 2450 & 3705 & 1.80 & 147.13 & 137.36 & 162.00 & & & \\
\hline \multirow[t]{4}{*}{$\mathrm{N}_{13}$} & P50 & 119.15 & 13.11 & 3.33 & 0.39 & 0.86 & 1296 & 1776 & 702 & 2.53 & 156.35 & 146.42 & 170.87 & 26 & 190 & 216 \\
\hline & QD & 46.27 & 0.22 & 0.48 & 0.02 & 0.09 & 139 & 44 & 66 & 0.23 & 1.33 & 1.45 & 1.16 & & & \\
\hline & P5 & 35.06 & 12.67 & 2.54 & 0.34 & 0.72 & 1178 & 1681 & 595 & 1.23 & 150.66 & 140.18 & 166.38 & & & \\
\hline & P95 & 170.20 & 13.93 & 5.99 & 0.48 & 1.19 & 2390 & 1931 & 1548 & 2.92 & 158.05 & 147.96 & 172.61 & & & \\
\hline \multirow[t]{4}{*}{$\mathrm{N}_{17}$} & P50 & 149.11 & 17.44 & 4.40 & 0.52 & 0.97 & 789 & 1144 & 490 & 2.35 & 159.56 & 151.11 & 177.30 & 462 & 3803 & 4265 \\
\hline & QD & 10.00 & 1.11 & 0.34 & 0.02 & 0.05 & 49 & 48 & 27 & 0.11 & 1.48 & 1.36 & 1.41 & & & \\
\hline & P5 & 141.53 & 16.04 & 4.02 & 0.50 & 0.93 & 765 & 1100 & 464 & 2.23 & 158.17 & 149.75 & 175.99 & & & \\
\hline & P95 & 179.74 & 19.31 & 5.42 & 0.64 & 1.82 & 957 & 1278 & 641 & 2.65 & 163.93 & 155.10 & 181.30 & & & \\
\hline
\end{tabular}

809 P50, median; P5 and P95, 5th percentile and 95th percentile, respectively; QD, quartile deviation;

810 Dur, duration; IPPI, inter-pulsepeak interval; $\tau_{95} \%$, duration of $95 \%$ cumulative energy; $\tau_{-3 \mathrm{~dB}}$ and $\tau_{\text {- }}$

$81110 \mathrm{~dB}$, duration of $-3 \mathrm{~dB}$ and $-10 \mathrm{~dB}$ of the peak amplitude of the enveloped signal, respectively; $\mathrm{f}_{\mathrm{p}}$,

812 peak frequency; $\mathrm{f}_{\mathrm{c}}$, center frequency; $\mathrm{BW}$ rms, centralized root-mean-square bandwidth; $\mathrm{Q}$, quality

813 factor; $\mathrm{SPL}_{\mathrm{zp}}$ and $\mathrm{SPL}_{\mathrm{rms}}$, zero-to-peak and root-mean-square sound pressure levels, respectively;

814 EFD, energy flux density; N1, N2 and N3, number of calls, inter-pulsepeak intervals and pulses 
816 and the EFD is in $\mathrm{dB}$ re $1 \mu \mathrm{Pa}^{2} \mathrm{~s}$. The IPIs are not shown here and can be obtained by subtracting 8

817 ms from the IPPIs. The same notation was used for the following tables.

Table 3 Descriptive statistics of sonic parameters of the ${ }^{i} N_{13}$ and ${ }^{i} N_{15}$ call types.

\begin{tabular}{|c|c|c|c|c|c|c|c|c|c|c|c|c|c|c|c|c|}
\hline & & Dur & IPPI & $\tau_{95 \%}$ & $\tau_{-3 \mathrm{~dB}}$ & $\begin{array}{l}\tau \\
10 \mathrm{~dB}\end{array}$ & $f_{p}$ & $f_{c}$ & $\mathrm{BW}_{\text {rms }}$ & Q & $\mathrm{SPL}_{z \mathrm{p}}$ & SPL $L_{r m s}$ & EFD & $\mathrm{N} 1$ & $\mathrm{~N} 2$ & N3 \\
\hline \multirow[t]{4}{*}{${ }^{i} \mathrm{~N}_{13}$} & P50 & 174.10 & 13.15 & 3.17 & 0.39 & 0.82 & 1490 & 1770 & 663 & 2.66 & 157.38 & 147.01 & 171.91 & 111 & 1266 & 1377 \\
\hline & QD & 17.49 & 0.35 & 0.42 & 0.03 & 0.13 & 217 & 49 & 52 & 0.22 & 2.09 & 2.05 & 1.91 & & & \\
\hline & P5 & 33.26 & 12.35 & 2.42 & 0.33 & 0.45 & 1184 & 1601 & 545 & 1.54 & 146.21 & 135.78 & 162.38 & & & \\
\hline & P95 & 202.23 & 15.37 & 5.75 & 0.60 & 1.31 & 2390 & 1930 & 1038 & 3.29 & 161.03 & 151.31 & 175.66 & & & \\
\hline \multirow[t]{4}{*}{${ }^{\mathrm{i}} \mathrm{N}_{15}$} & P50 & 169.31 & 14.96 & 3.12 & 0.41 & 0.42 & 1510 & 1787 & 929 & 1.95 & 142.26 & 133.21 & 157.60 & 16 & 158 & 174 \\
\hline & QD & 19.04 & 1.51 & 0.33 & 0.10 & 0.15 & 167 & 47 & 122 & 0.22 & 2.89 & 2.47 & 2.69 & & & \\
\hline & P5 & 139.67 & 13.55 & 2.70 & 0.24 & 0.20 & 1283 & 1750 & 823 & 1.70 & 140.50 & 131.32 & 155.86 & & & \\
\hline & P95 & 192.87 & 19.30 & 5.30 & 0.57 & 0.65 & 2202 & 2362 & 2059 & 2.98 & 152.37 & 143.35 & 167.28 & & & \\
\hline
\end{tabular}

Table 4 Descriptive statistics of sonic parameters of the $1+N_{10}, 1+N_{12}$ and $1+N_{19}$ call types.

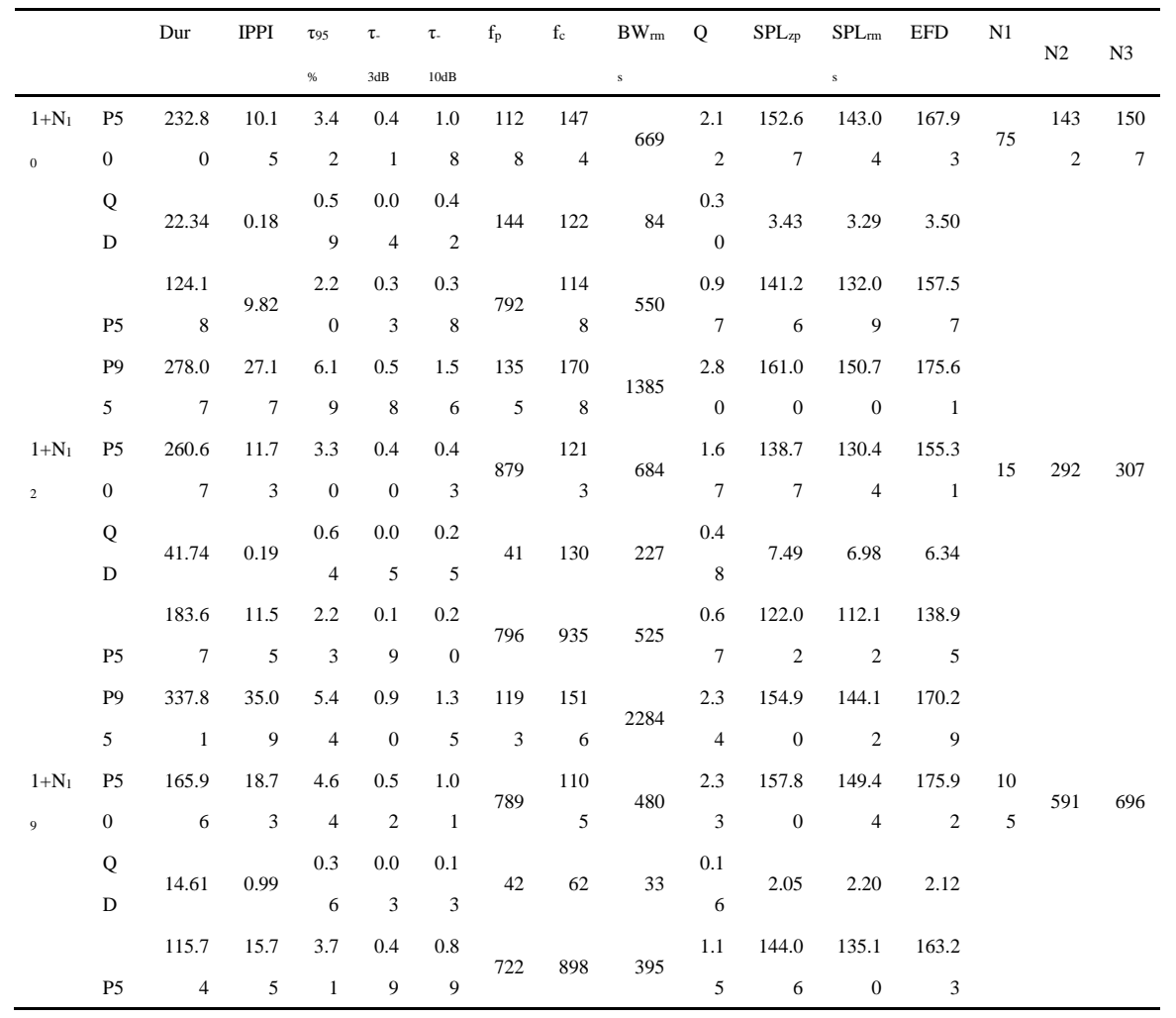



821 Table 5 Frequency and inter-pulsepeak interval (IPPI) characteristics of soniferous fish in the Pearl River Estuary.

\begin{tabular}{|c|c|c|c|c|c|c|c|c|c|c|}
\hline Family & $\underline{\text { Species }}$ & Latin name & Condition & Peak frequency & IPPI & First IPPI & Last IPPI & $\begin{array}{l}\text { No. } \\
\text { signal }\end{array}$ & $\underline{\text { Comments }}$ & Reference \\
\hline \multirow[t]{22}{*}{$\underline{\underline{S c i a e n i d a e}}$} & Belanger's croaker & $\underline{\text { Johnius belangerii }}$ & Voluntary & 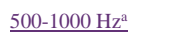 & & $40 \mathrm{~ms}$ & $20 \mathrm{~ms}^{\mathrm{e}}$ & & & Pilleri et al. 1982 \\
\hline & & & & $750-1250 \mathrm{~Hz}$ & & & & & long burst & Pilleri et al. 1982 \\
\hline & & & Disturbance & $\underline{584 \pm 181 \mathrm{~Hz}}$ & $12.9 \mathrm{~ms}$ & $14.4 \mathrm{~ms}$ & $16.9 \mathrm{~ms}$ & $\underline{200}$ & & Mok et al. 2011a \\
\hline & Big-snout croaker & J. macrorhynus & Voluntary & $1146 \pm 131 \mathrm{~Hz}$ & & $40.1 \mathrm{~ms}$ & $9.7 \mathrm{~ms}^{\mathrm{e}}$ & $\underline{40}$ & purr signals ${ }^{\mathrm{c}}$ & Lin et al. 2007 \\
\hline & & & Voluntary & $\underline{1050 \pm 84 \mathrm{~Hz}}$ & & $35.3 \mathrm{~ms}$ & $\underline{10.4 \mathrm{~ms}^{\mathrm{e}}}$ & $\underline{40}$ & purr signal $^{d}$ & Lin et al. 2007 \\
\hline & & & $\underline{\text { Voluntary }}$ & $\underline{1133 \pm 119 \mathrm{~Hz}}$ & $36.7 \mathrm{~ms}$ & & & $\underline{15}$ & $\underline{\text { dual-knocks }}^{\mathrm{c}}$ & Lin et al. 2007 \\
\hline & & & Voluntary & $1135 \pm 85 \mathrm{~Hz}$ & $39.4 \mathrm{~ms}$ & & & $\underline{15}$ & dual-knocks $^{\mathrm{d}}$ & Lin et al. 2007 \\
\hline & & & Disturbance & $\underline{808 \pm 142 \mathrm{~Hz}}$ & & $22.2 \mathrm{~ms}$ & $9.5 \mathrm{~ms}^{\mathrm{e}}$ & $\underline{40}$ & purr signals & Lin et al. 2007 \\
\hline & & & Disturbance & $807 \pm 143 \mathrm{~Hz}$ & $\underline{10.1}$ & $22.2 \mathrm{~ms}$ & $10.5 \mathrm{~ms}$ & $\underline{85}$ & & Mok et al. 2011a \\
\hline & & & Disturbance & $\underline{425.9 \pm 93.7 \mathrm{~Hz}}$ & & $19.2 \pm 7.3 \mathrm{~ms}$ & & $\underline{352}$ & male+female & Huang et al. 2016 \\
\hline & & & Disturbance & $450.9 \pm 106.1 \mathrm{~Hz}$ & & $20.5 \pm 8.2 \mathrm{~ms}$ & & $\underline{210}$ & male & Huang et al. 2016 \\
\hline & & & Disturbance & $\underline{386.5 \pm 57.1 \mathrm{~Hz}}$ & & $\underline{8.0 \pm 1.4 \mathrm{~ms}}$ & & $\underline{142}$ & female & $\underline{\text { Huang et al. } 2016}$ \\
\hline & & $\underline{J . s p .}$. & Disturbance & $454.0 \pm 33.7 \mathrm{~Hz}$ & & $\underline{12.8 \pm 6.4 \mathrm{~ms}}$ & & $\underline{28}$ & male+female & Huang et al. 2016 \\
\hline & & & Disturbance & $454.0 \pm 33.7 \mathrm{~Hz}$ & & $\underline{10.6 \pm 1.8 \mathrm{~ms}}$ & & $\underline{25}$ & male & Huang et al. 2016 \\
\hline & & & Disturbance & $2249.9 \pm 584.6 \mathrm{~Hz}$ & & $22.6 \pm 10.5 \mathrm{~ms}$ & & $\underline{5}$ & female & Huang et al. 2016 \\
\hline & $\underline{\text { Sciaenidae }}$ & J. distincus & Disturbance & $\underline{839 \pm 144 \mathrm{~Hz}}$ & & $9.97 \pm 0.72 \mathrm{~ms}$ & $\underline{12.36 \pm 0.53 \mathrm{~ms}}$ & & male & $\underline{\text { Tsai } 2009}$ \\
\hline & & & Disturbance & $\underline{581 \pm 66 \mathrm{~Hz}}$ & & $10.12 \pm 0.82 \mathrm{~ms}$ & $12.53 \pm 0.79 \mathrm{~ms}$ & $\underline{210}$ & female & Tsai 2009 \\
\hline & & & Disturbance & & $10.8 \mathrm{~ms}$ & $\underline{11.1 \mathrm{~ms}}$ & $\underline{12.3 \mathrm{~ms}}$ & $\underline{242}$ & & Mok et al. 2011a \\
\hline & & & Disturbance & $392.4 \pm 100.0 \mathrm{~Hz}$ & & $13.4 \pm 4.8 \mathrm{~ms}$ & & $\underline{524}$ & $\underline{\text { male+female }}$ & Huang et al. 2016 \\
\hline & & & Disturbance & $398.1 \pm 94.0 \mathrm{~Hz}$ & & $14.3 \pm 2.3 \mathrm{~ms}$ & & $\underline{273}$ & $\underline{\text { male }}$ & Huang et al. 2016 \\
\hline & & & Disturbance & $352.1 \pm 84.2 \mathrm{~Hz}$ & & $11.6 \pm 2.7 \mathrm{~ms}$ & & $\underline{183}$ & female & Huang et al. 2016 \\
\hline & & J.amblycephalus & Disturbance & $\underline{367.1 \pm 100.8 \mathrm{~Hz}}$ & & $\underline{14.5 \pm 3.6 \mathrm{~ms}}$ & & $\underline{58}$ & & Huang et al. 2016 \\
\hline
\end{tabular}




\begin{tabular}{|c|c|c|c|c|c|c|c|c|c|}
\hline$\underline{\text { Sin croaker }}$ & $\underline{\text { J. dussumieri }}$ & Disturbance & $\underline{517 \mathrm{~Hz}}$ & & $\underline{11.4 \mathrm{~ms}}$ & $14.9 \mathrm{~ms}$ & & & $\underline{\text { Tsai } 2009}$ \\
\hline White croaker & Pennahia argentata & Voluntary & $457 \mathrm{~Hz}$ & & & & & male & Ramcharitar et al. 2006 \\
\hline & & Voluntary & $267 \mathrm{~Hz}$ & & & & & female & Ramcharitar et al. 2006 \\
\hline & & Disturbance & $\underline{543 \pm 98 \mathrm{~Hz}}$ & $\underline{22.9 \mathrm{~ms}}$ & $\underline{24.0 \mathrm{~ms}}$ & $37.9 \mathrm{~ms}$ & $\underline{104}$ & & $\underline{\text { Mok et al. 2011a }}$ \\
\hline & & Disturbance & $\underline{348.6 \pm 18.1 \mathrm{~Hz}}$ & & $9.4 \pm 0.3 \mathrm{~ms}$ & & $\underline{23}$ & female & Huang et al. 2016 \\
\hline Greyfin croaker & P. anea & Disturbance & $\underline{736 \pm 115 \mathrm{~Hz}}$ & $10.6 \mathrm{~ms}$ & $9.1 \mathrm{~ms}$ & $\underline{12.1 \mathrm{~ms}}$ & $\underline{90}$ & & Mok et al. 2011a \\
\hline & & Disturbance & $551.9 \pm 27.7 \mathrm{~Hz}$ & & $\underline{10.9 \pm 1.6 \mathrm{~ms}}$ & & $\underline{15}$ & female & Huang et al. 2016 \\
\hline & & Disturbance & $\underline{450.9 \pm 106.1 \mathrm{~Hz}}$ & & $20.5 \pm 8.2 \mathrm{~ms}$ & & $\underline{210}$ & male & Huang et al. 2016 \\
\hline & & Disturbance & $\underline{386.5 \pm 57.1 \mathrm{~Hz}}$ & & $\underline{8.0 \pm 1.4 \mathrm{~ms}}$ & & $\underline{142}$ & female & Huang et al. 2016 \\
\hline Pawak croaker & P. pawak & Disturbance & $\underline{736 \pm 101 \mathrm{~Hz}}$ & $9.1 \mathrm{~ms}$ & $8.5 \mathrm{~ms}$ & $9.7 \mathrm{~ms}$ & 169 & & Mok et al. 2011a \\
\hline & & Disturbance & $\underline{388.1 \pm 41.6 \mathrm{~Hz}}$ & & $\underline{11.2 \pm 2.1 \mathrm{~ms}}$ & & $\underline{15}$ & female & Huang et al. 2016 \\
\hline Large yellow croaker & Pseudosciaena crocea & Voluntary & $\underline{550-750 \mathrm{~Hz}^{\mathrm{a}}}$ & & & & $\underline{182}$ & single pulse & Liu et al. 2010 \\
\hline & & Voluntary & $\underline{587 \pm 190 \mathrm{~Hz}}$ & $\underline{23 \pm 3 \mathrm{~ms}}$ & & & $\underline{164}$ & female & Ueng et al. 2007 \\
\hline$\underline{\text { Yellow Drum }}$ & Nibea albiflora & $\underline{\text { Voluntary }}$ & $650 \pm 20 \mathrm{~Hz}$ & & & & & & $\underline{\text { Ren et al. } 2007}$ \\
\hline & & Disturbance & $293.1 \pm 56.4 \mathrm{~Hz}$ & & $\underline{12.2 \pm 2.2 \mathrm{~ms}}$ & & $\underline{23}$ & & Huang et al. 2016 \\
\hline Reeve's croaker & N. acuta & Voluntary & $\underline{630 \pm 15 \mathrm{~Hz}}$ & & & & & & $\underline{\text { Ren et al. } 2007}$ \\
\hline & & Disturbance & $\leq 500 \mathrm{~Hz}^{\mathrm{a}}$ & & & & & & $\underline{\text { Tsai } 2009}$ \\
\hline$\underline{\text { Tiger-toothed croaker }}$ & Otolithes ruber & Disturbance & $\underline{354-1717 \mathrm{~Hz}^{\mathrm{a}}}$ & $\underline{8.3-12.2 \mathrm{~ms}^{\mathrm{a}}}$ & & & $\underline{17}$ & & $\underline{\text { Mok et al. 2011a }}$ \\
\hline Blackmouth croaker & Atrobucca nibe & Disturbance & & $\underline{47.0-57.8 \mathrm{~ms}^{\mathrm{a}}}$ & & & 1 & & Mok et al. 2011a \\
\hline
\end{tabular}




\begin{tabular}{|c|c|c|c|c|c|c|c|}
\hline$\underline{\text { Trichiuridae }}$ & Cutlassfish & $\underline{\text { Trichiurus haumela }}$ & Voluntary & $\underline{628 \pm 11 \mathrm{~Hz}}$ & & & Ren et al. 2007 \\
\hline Pristigasteridae & Elongate ilisha & Ilisha elongata & $\underline{\text { Voluntary }}$ & $\underline{251 \pm 18 \mathrm{~Hz}}$ & & & Ren et al. 2007 \\
\hline \multirow[t]{2}{*}{$\underline{\text { Ariidae }}$} & $\underline{\text { Sea cattish }}$ & Arius sp. & Voluntary & $\underline{735 \pm 12 \mathrm{~Hz}}$ & & & Ren et al. 2007 \\
\hline & & A. maculates & Disturbance & & $\underline{0.47-4.33 \mathrm{~ms}^{\mathrm{ab}}}$ & 5-11 pulse signal & Mok et al. 2011a \\
\hline Glaucosomatidae & Pearl perch & Glaucosoma buergeri & Disturbance & & $30 \mathrm{~ms}$ & 2-9 pulse signal & Mok et al. 2011b \\
\hline$\underline{\text { Priacanthidae }}$ & Bigeye snapper & Priacanthus macracanthus & Disturbance & $\underline{172 \mathrm{~Hz}}$ & $\underline{15.9 \mathrm{~ms}}$ & & $\underline{\text { Tsai } 2009}$ \\
\hline Terapontidae & Trumpeter perch & Pelates quadrilineatus & Disturbance & $\underline{690 \pm 171 \mathrm{~Hz}}$ & $4 \mathrm{~ms}$ & & $\underline{\text { Tsai } 2009}$ \\
\hline Haemulidae & Javelin grunter & Pomadasys kaakan & Disturbance & & $94.1 \mathrm{~ms}$ & & $\underline{\text { Tsai } 2009}$ \\
\hline
\end{tabular}

824 Except when mentioned, the results are given as the mean or mean \pm standard deviation(sd)

825 The superscript a denotes results given in a range.

826 The superscript $b$ denotes results given for the inter-pulse interval.

827 The superscript $\mathrm{c}$ denotes results recorded in the field.

828 The superscript $d$ denotes results recorded in a large aquarium.

829 The superscripts e denotes results that are the mean of all the IPPIs except the first IPPI. 


\section{Supporting information}

Fig. S1 Characteristic of the (A) 2 and (B) 1+1 call types. Rows 1 and 2 are the oscillogram and sonogram, respectively, of a representative signal for each call type. Row 3 is the duration of a call as a function of the number of pulses within the call. Rows 4 is the pooled inter-pulsepeak interval of each pulse versus the order at which it occurs within a call. For the boxplot, the line inside the box indicates the median value, and the upper and lower box borders are the first and third quartiles, respectively. The length of the box is the interquartile range (IQR). The whiskers extend to the most extreme data within the limit of 1.5 IQRs from the end of the box. Open circles (o) denote mild outliers with values greater than 1.5 IQRs but fewer than 3 IQRs from the end of the box. Asterisks (*) denote extreme outliers with values greater than 3 box lengths from the upper or lower edges of the box. Sonogram configuration: FFT size, 96,000; window type, Hanning; overlap samples per frame, $95 \%$.

Table S1 Descriptive statistics of the sonic parameters of single and paired pulse call types. P50, median; P5 and P95, 5th percentile and 95th percentile, respectively; QD, quartile deviation; Dur, duration; IPPI, inter-pulsepeak interval; $\tau_{95 \%}$, duration of $95 \%$ cumulative energy; $\tau_{-3 \mathrm{~dB}}$ and $\tau_{-}$ $10 \mathrm{~dB}$, duration of $-3 \mathrm{~dB}$ and $-10 \mathrm{~dB}$ of the peak amplitude of the enveloped signal, respectively; $\mathrm{f}_{\mathrm{p}}$, peak frequency; $\mathrm{f}_{\mathrm{c}}$, center frequency; $\mathrm{BW}_{\mathrm{rms}}$, centralized root-mean-square bandwidth; $\mathrm{Q}$, quality factor; $\mathrm{SPL}_{\mathrm{zp}}$ and SPL $\mathrm{L}_{\mathrm{rms}}$, zero-to-peak and root-mean-square sound pressure levels, respectively; EFD, energy flux density; N1, N2 and N3, number of calls, inter-pulsepeak intervals and pulses analyzed, respectively. The duration is in seconds, the frequency is in $\mathrm{Hz}$, the SPL is in $\mathrm{dB}$ re $1 \mu \mathrm{Pa}$, and the EFD is in $\mathrm{dB}$ re $1 \mu \mathrm{Pa}^{2} \mathrm{~s}$. The IPIs are not shown here and can be obtained by subtracting 8 ms from the IPPIs. The same notation was used for the following tables. 
Fig. S2 Characteristic of the (A) $2+\mathbf{N}_{9}$, (B) $2+\mathbf{N}_{10}$ and (C) $2+\mathbf{N}_{18}$ call types. Rows 1 and 2 are the oscillogram and sonogram, respectively, of a representative signal for each call type. Row 3 is the duration of a call as a function of the number of pulses within the call. Rows 4 is the pooled interpulsepeak interval of each pulse versus the order at which it occurs within a call.

\section{Table S2 Descriptive statistics of sonic parameters of the $2+N_{9}, 2+N_{10}$ and $2+N_{18}$ call types.}

Fig. S3 Characteristic of the (A) $3+\mathbf{N}_{9}$, (B) $3+\mathbf{N}_{10}$ and (C) $3+\mathbf{N}_{17}$ call types. Rows 1 and 2 are the oscillogram and sonogram, respectively, of a representative signal for each call type. Row 3 is the duration of a call as a function of the number of pulses within the call. Rows 4 is the pooled interpulsepeak interval of each pulse versus the order at which it occurs within a call.

Table S3 Descriptive statistics of sonic parameters of the $3+N_{9}, 3+N_{10}$ and $3+N_{17}$ call types.

Fig. S4 Characteristic of the (A) $4+N_{9}$, (B) $4+N_{10}$ and (C) $4+N_{17}$ call types. Rows 1 and 2 are the oscillogram and sonogram, respectively, of a representative signal for each call type. Row 3 is the duration of a call as a function of the number of pulses within the call. Rows 4 is the pooled interpulsepeak interval of each pulse versus the order at which it occurs within a call.

Table S4 Descriptive statistics of sonic parameters of the $4+N_{9}, 4+N_{10}$ and $4+N_{17}$ call types.

Fig. S5 Characteristic of the $\mathbf{5}+\mathbf{N}_{\mathbf{1 0}}$ call type. Rows 1 and 2 are the oscillogram and sonogram, respectively, of a representative signal for each call type. Row 3 is the duration of a call as a function of the number of pulses within the call. Rows 4 is the pooled inter-pulsepeak interval of each pulse versus the order at which it occurs within a call.

\section{Table S5 Descriptive statistics of sonic parameters of $5+N_{10}$ call type.}

Fig. S6 Characteristic of the (A) $(1-)^{2}+N_{9}$, (B) $(1-)^{2}+N_{10}$ and (C) (1- $)^{2}+\mathbf{N}_{12}$ call type. Rows 1 and 2 are the oscillogram and sonogram, respectively, of a representative signal for each call type. Row 
3 is the duration of a call as a function of the number of pulses within the call. Rows 4 is the pooled inter-pulsepeak interval of each pulse versus the order at which it occurs within a call.

Table S6 Descriptive statistics of sonic parameters of the $(1-)^{2}+N_{9},(1-)^{2}+N_{10}$ and $(1-)^{2}+N_{12}$ call types.

Fig. S7 Characteristic of the (A) $1+2+\mathbf{N}_{10}$ and (B) $1+2+\mathbf{N}_{18}$ call types. Rows 1 and 2 are the oscillogram and sonogram, respectively, of a representative signal for each call type. Row 3 is the duration of a call as a function of the number of pulses within the call. Rows 4 is the pooled interpulsepeak interval of each pulse versus the order at which it occurs within a call.

Table S7 Descriptive statistics of sonic parameters of the $1+2+N_{10}$ and $1+2+N_{18}$ call types. Fig. S8 Characteristic of the (A) $\mathbf{2}+\mathbf{1}+\mathbf{N}_{9}$ and (B) $\mathbf{2}+\mathbf{1}+\mathbf{N}_{10}$ call types. Rows 1 and 2 are the oscillogram and sonogram, respectively, of a representative signal for each call type. Row 3 is the duration of a call as a function of the number of pulses within the call. Rows 4 is the pooled interpulsepeak interval of each pulse versus the order at which it occurs within a call.

Table S8 Descriptive statistics of sonic parameters of the $2+1+N_{9}$ and $2+1+N_{10}$ call types.

Fig. S9 Characteristic of the (A) $(2-)^{2}+\mathbf{N}_{10}$ and (B) $4+1+\mathbf{N}_{10}$ call types. Rows 1 and 2 are the oscillogram and sonogram, respectively, of a representative signal for each call type. Row 3 is the duration of a call as a function of the number of pulses within the call. Rows 4 is the pooled interpulsepeak interval of each pulse versus the order at which it occurs within a call.

Table S9 Descriptive statistics of sonic parameters of the $(2-)^{2}+N_{10}$ and $4+1+N_{10}$ call types. Fig. S10 Characteristic of the (A) $3+1+N_{9}$ and (B) $3+1+N_{10}$ call types. Rows 1 and 2 are the oscillogram and sonogram, respectively, of a representative signal for each call type. Row 3 is the duration of a call as a function of the number of pulses within the call. Rows 4 is the pooled interpulsepeak interval of each pulse versus the order at which it occurs within a call.

Table S10 Descriptive statistics of sonic parameters of the $3+1+N_{9}$ and $3+1+N_{10}$ call types. 
Fig. S11 Characteristic of the (A) $3+2+N_{9}$ and (B) $3+(1-)^{2}+N_{9}$ call types. Rows 1 and 2 are the oscillogram and sonogram, respectively, of a representative signal for each call type. Row 3 is the duration of a call as a function of the number of pulses within the call. Rows 4 is the pooled interpulsepeak interval of each pulse versus the order at which it occurs within a call.

Table S11 Descriptive statistics of sonic parameters of the $3+2+N_{9}$ and $3+(1-)^{2}+N_{9}$ call types. Fig. S12 Characteristic of the (A) $(1-)^{3}+\mathrm{N}_{9}$, (B) $(1-)^{3}+\mathrm{N}_{10}$ and (C) $(1-)^{3}+\mathrm{N}_{12}$ call types. Rows 1 and 2 are the oscillogram and sonogram, respectively, of a representative signal for each call type. Row 3 is the duration of a call as a function of the number of pulses within the call. Rows 4 is the pooled inter-pulsepeak interval of each pulse versus the order at which it occurs within a call.

Table S12 Descriptive statistics of sonic parameters of the $(1-)^{3}+N_{9},(1-)^{3}+N_{10}$ and $(1-)^{3}+N_{12}$ call types.

Fig. S13 Characteristic of the (A) $(1-)^{2}+2+N_{9}$ and (B) $(1-)^{2}+2+N_{10}$ call types. Rows 1 and 2 are the oscillogram and sonogram, respectively, of a representative signal for each call type. Row 3 is the duration of a call as a function of the number of pulses within the call. Rows 4 is the pooled inter-pulsepeak interval of each pulse versus the order at which it occurs within a call.

Table S13 Descriptive statistics of sonic parameters of the $(1-)^{2}+2+\mathrm{N}_{9}$ and $(1-)^{2}+2+\mathrm{N}_{10}$ call types.

Fig. S14 Characteristic of the $(\mathbf{1 -})^{2}+3+N_{10}$ call type. Rows 1 and 2 are the oscillogram and sonogram, respectively, of a representative signal for each call type. Row 3 is the duration of a call as a function of the number of pulses within the call.

Table S14 Descriptive statistics of sonic parameters of the $(1-)^{2}+3+\mathrm{N}_{10}$ call type.

Fig. S15 Characteristic of the (A) $2+(1-)^{2}+N_{9}$ and (B) $2+(1-)^{2}+N_{10}$ call types. Rows 1 and 2 are the oscillogram and sonogram, respectively, of a representative signal for each call type. Row 3 is the duration of a call as a function of the number of pulses within the call. Rows 4 is the pooled inter-pulsepeak interval of each pulse versus the order at which it occurs within a call. 
Table S15 Descriptive statistics of sonic parameters of the $2+(1-)^{2}+N_{9}$ and $2+(1-)^{2}+N_{10}$ call types.

Fig. S16 Characteristic of the (A) $2+1+2+N_{9}$ and (B) $2+1+2+N_{10}$ call types. Rows 1 and 2 are the oscillogram and sonogram, respectively, of a representative signal for each call type. Row 3 is the duration of a call as a function of the number of pulses within the call. Rows 4 is the pooled interpulsepeak interval of each pulse versus the order at which it occurs within a call.

Table S16 Descriptive statistics of sonic parameters of the $2+1+2+\mathrm{N}_{9}$ and $2+1+2+\mathrm{N}_{10}$ call types. Fig. S17 Characteristic of the (A) $(1-)^{4}+\mathbf{N}_{9},(B)(1-)^{4}+\mathbf{N}_{10}$ and (C) $(1-)^{4}+\mathbf{N}_{12}$ call types. Rows 1 and 2 are the oscillogram and sonogram, respectively, of a representative signal for each call type. Row 3 is the duration of a call as a function of the number of pulses within the call. Rows 4 is the pooled inter-pulsepeak interval of each pulse versus the order at which it occurs within a call.

Table S17 Descriptive statistics of sonic parameters of the $(1-)^{4}+N_{9},(1-)^{4}+N_{10}$ and $(1-)^{4}+N_{12}$ call types.

Fig. S18 Characteristic of the (A) $(1-)^{3}+2+\mathbf{N}_{10}$ and (B) $(1-)^{3}+3+\mathbf{N}_{10}$ call types. Rows 1 and 2 are the oscillogram and sonogram, respectively, of a representative signal for each call type. Row 3 is the duration of a call as a function of the number of pulses within the call. Rows 4 is the pooled inter-pulsepeak interval of each pulse versus the order at which it occurs within a call.

Table S18 Descriptive statistics of sonic parameters of the $(1-)^{3}+2+N_{10}$ and $(1-)^{3}+3+N_{10}$ call types.

Fig. S19 Characteristic of the (A) $(1-)^{2}+2+1+N_{10}$ and (B) $(1-)^{2}+2+3+N_{10}$ call types. Rows 1 and 2 are the oscillogram and sonogram, respectively, of a representative signal for each call type. Row 3 is the duration of a call as a function of the number of pulses within the call.

Table S19 Descriptive statistics of sonic parameters of the $(1-)^{2}+2+1+\mathrm{N}_{10}$ and $(1-)^{2}+2+3+\mathrm{N}_{10}$ call types.

Fig. S20 Characteristic of the (A) $2+(1-)^{3}+\mathbf{N}_{10}$ and (B) $2+(1-)^{4}+\mathbf{N}_{10}$ call types. Rows 1 and 2 are the oscillogram and sonogram, respectively, of a representative signal for each call type. Row 3 is the duration of a call as a function of the number of pulses within the call. Rows 4 is the pooled 
inter-pulsepeak interval of each pulse versus the order at which it occurs within a call.

Table S20 Descriptive statistics of sonic parameters of the $2+(1-)^{3}+\mathrm{N}_{10}$ and $2+(1-)^{4}+\mathrm{N}_{10}$ call types.

Fig. S21 Characteristic of the (A) $(1-)^{5}+\mathbf{N}_{9}$ and (B) $(1-)^{5}+\mathbf{N}_{10}$ call types. Rows 1 and 2 are the oscillogram and sonogram, respectively, of a representative signal for each call type. Row 3 is the duration of a call as a function of the number of pulses within the call. Rows 4 is the pooled interpulsepeak interval of each pulse versus the order at which it occurs within a call.

Table S21 Descriptive statistics of sonic parameters of the $(1-)^{5}+\mathrm{N}_{9}$ and $(1-)^{5}+\mathrm{N}_{10}$ call types.

Fig. S22 Characteristic of the (A) $(1-)^{4}+2+\mathbf{N}_{10}$ and (B) $(1-)^{4}+3+\mathbf{N}_{11}$ call types. Rows 1 and 2 are the oscillogram and sonogram, respectively, of a representative signal for each call type. Row 3 is the duration of a call as a function of the number of pulses within the call. Rows 4 is the pooled inter-pulsepeak interval of each pulse versus the order at which it occurs within a call.

Table S22 Descriptive statistics of sonic parameters of the $(1-)^{4}+2+\mathrm{N}_{10}$ and $(1-)^{4}+3+\mathrm{N}_{11}$ call types.

Fig. S23 Characteristic of the (A) $(1-)^{3}+2+1+N_{10}$ and (B) $(1-)^{4}+2+1+N_{10}$ call types. Rows 1 and 2 are the oscillogram and sonogram, respectively, of a representative signal for each call type. Row 3 is the duration of a call as a function of the number of pulses within the call. Rows 4 is the pooled inter-pulsepeak interval of each pulse versus the order at which it occurs within a call.

Table S23 Descriptive statistics of sonic parameters of the $(1-)^{3}+2+1+N_{10}$ and $(1-)^{4}+2+1+N_{10}$ call types.

Fig. S24 Characteristic of the (A) $(1-)^{6}+\mathbf{N}_{10}$ and (B) $(1-)^{7}+\mathbf{N}_{10}$ call types. Rows 1 and 2 are the oscillogram and sonogram, respectively, of a representative signal for each call type. Row 3 is the duration of a call as a function of the number of pulses within the call. Rows 4 is the pooled inter- 
pulsepeak interval of each pulse versus the order at which it occurs within a call.

Table S24 Descriptive statistics of sonic parameters of the $(1-)^{6}+N_{10}$ and $(1-)^{7}+N_{10}$ call types.

Fig. S25 Characteristic of the (A) $(1-)^{5}+2+N_{10}$ and $(B)(1-)^{5}+3+N_{10}$ call types. Rows 1 and 2 are the oscillogram and sonogram, respectively, of a representative signal for each call type. Row 3 is the duration of a call as a function of the number of pulses within the call. Rows 4 is the pooled inter-pulsepeak interval of each pulse versus the order at which it occurs within a call.

Table S25 Descriptive statistics of sonic parameters of the $(1-)^{5}+2+N_{10}$ and $(1-)^{5}+3+N_{10}$ call types.

Fig. S26 Characteristic of the (A) $(1-)^{4}+(2-)^{2}+N_{10}$ and (B) $(1-)^{5}+(2-)^{2}+N_{10}$ call types. Rows 1 and 2 are the oscillogram and sonogram, respectively, of a representative signal for each call type. Row 3 is the duration of a call as a function of the number of pulses within the call. Rows 4 is the pooled inter-pulsepeak interval of each pulse versus the order at which it occurs within a call.

Table S26 Descriptive statistics of sonic parameters of the $(1-)^{4}+(2-)^{2}+\mathrm{N}_{10}$ and $(1-)^{5}+(2-)^{2}+\mathrm{N}_{10}$ call types.

Fig. S27 Relative abundance of the 66 call types.

Fig. 228 Distribution pattern of the inter-pulspeak interval of each pulse versus the order at which it occurs within a call of all $\mathrm{N}_{9}$ and $\mathrm{N}_{10}$ call types. 